Research article

\title{
Response of dune mobility and pedogenesis to fluctuations in monsoon precipitation and human activity in the Hulunbuir dune field, northeastern China, since the last deglaciation
}

\author{
Lin Zeng ${ }^{\mathrm{a}, \mathrm{b}, \mathrm{c}, *}$, Shuangwen $\mathrm{Yi}^{\mathrm{c}, *}$, Huayu $\mathrm{Lu}^{\mathrm{c}}$, Yingyong Chen ${ }^{\mathrm{d}}$, Fang Lei ${ }^{\mathrm{c}}$, Zhiwei $\mathrm{Xu}^{\mathrm{c}}$, \\ Xianyan Wang ${ }^{c}$, Wenfang Zhang ${ }^{\mathrm{e}}$ \\ a Institute of Soil Science, Chinese Academy of Sciences, Nanjing 210008, China \\ ${ }^{\mathbf{b}}$ Key Laboratory of Coastal Environmental Processes and Ecological Remediation, Yantai Institute of Coastal Zone Research, Chinese Academy of Sciences, Yantai \\ 264003, China \\ ${ }^{\mathrm{c}}$ School of Geography and Ocean Science, Nanjing University, Nanjing 210023, China \\ d ${ }^{\mathrm{d}}$ The College of Environment and Planning of Henan University, Kaifeng, 475004, China \\ ${ }^{\mathrm{e}}$ State Key Laboratory of Lake Science and Environment, Nanjing Institute of Geography and Limnology, Chinese Academy of Sciences, Nanjing 210008, China
}

\section{A R T I C L E I N F O}

\section{Keywords:}

Dune activity

OSL dating

Hulunbuir dune field

East Asian monsoon

human activity

\begin{abstract}
A B S T R A C T
The Hulunbuir dune field is located at the northern margin of the temperate monsoon zone in East Asia, and changes in dune activity and pedogenesis in the dune field are highly sensitive to the advance and retreat of the East Asian summer monsoon (EASM) and to human activity. Thus, the stratigraphic sequences of paleosol and aeolian sand of the dune field have great potential for reconstructing the history of dune activity and pedogenesis and their response to past fluctuations in monsoon precipitation and the intensity of human activity. However, our knowledge of the evolution of the landscape and paleoclimate of the dune field is limited. Here, we present the results of analyses of quartz optically stimulated luminescence (OSL), grain size and magnetic susceptibility (MS) from 13 representative sections in the Hulunbuir dune field. The grain-size analysis indicates that the sand layers are composed of typical aeolian sand, and the MS variations of the aeolian sand and sandy paleosol sequences mainly reflect changes in the intensity of pedogenesis. We combine our new OSL dating results with previously published OSL ages to refine the chronology of sand dune development. An OSL age hiatus in both aeolian sand and paleosol during the 5-7 ka indicates that aeolian deposition in Hulunbuir ceased almost completely during this period, which corresponds to the peak in EASM strength. Thus, our study provides new evidence for a delayed response of the EASM maximum to peak insolation forcing (11-10 ka) in the midlatitude monsoon margin. In addition, we speculate that peaks in probability density (PD) from 1.2-0.7 ka and from $0.25-0 \mathrm{ka}$ of aeolian sand accumulation correspond to population increases and the development of cultivation and animal husbandry in the Hulunbuir dune field.
\end{abstract}

\section{Introduction}

Forty-seven percent of the earth's surface has an arid and semi-arid climate, and persistent and severe drought have led to vegetation degradation and desertification in such regions (Lancaster and Hallward, 1984; Barakat, 2009; Pye and Tsoar, 2009). Nearly two billion people live in the arid and semi-arid regions, and desertification as the primary ecological and environmental problem seriously affects human survival and development (UNDP/UNCCD, 2010). The landscape and aeolian activity of the sandy desert/dune fields in these regions varies on timescales of millions of years to decades, reflecting tectonic movements, climate change, and human activity (e.g., Guo et al., 2002; Ding et al., 2005; Lu et al., 2005; Mason et al., 2008). The intensity of aeolian activity can significantly change the extent of sandy desert and dune fields, manifested by the spatial expansion and contraction of the desert boundary (Lu et al., 2013b). As a result, such large-scale changes in the land surface can significantly alter the surface albedo and thus influence the energy budget which affects the regional and potentially even the global climate (Charney et al., 1977; Dickinson, 1983; Rodwell and Hoskins, 1996).

The sandy deserts and sand dune systems of northern China are also the primary source area of Asian mineral dust and changes in their

\footnotetext{
* Corresponding authors at: School of Geography and Ocean Science, Nanjing University, Nanjing 210023, China.

E-mail addresses: zenglin_geo@qq.com (L. Zeng), ysw7563@nju.edu.cn (S. Yi).
} 
surface characteristics and spatial extent will influence the quantity of dust emission. In turn, this potentially affects the net primary productivity of the Northern Hemisphere oceans and the global biogeochemical cycle through the supply of mineral dust particles, and associated nutrients, via long-distance transmission as part of the atmospheric circulation (Jickells et al., 2005; Shao et al., 2011; Serno et al., 2014; Zhao et al., 2015) Therefore, research on the environmental evolution of the sandy desert/dune fields not only provides essential data for local and regional administration departments, as well as contributing to scientific decision-making for desertification control to promote the improvement of the regional ecological environment, but it also enhances our understanding of the response and feedback mechanisms associated with regional and global environmental change.

The evolution of the East Asian summer monsoon (EASM) is a major topic in geoscience (An et al., 2013; Chen et al., 2015; Wang et al., 2017). Changes in EASM circulation have significantly impacted the evolution of civilization and socioeconomic development in the monsoon area since the last deglaciation (Zhang et al., 2008; Cook et al., 2010; Dong et al., 2012). Thus, further study of changes in EASM circulation since the last deglaciation could contribute to distinguish natural variability from anthropogenic forcing and provide an important reference for understanding and predicting long-term future trends in the EASM, especially under climate warming scenarios. In the last two decades, EASM variability has been reconstructed through the study of a variety of paleoclimate archives and proxy indicators, including loess-paleosol sequences (e.g., An et al., 1991; Liu and Ding, 1998; Sun et al., 2006b; Guo et al., 2009; Hao et al., 2012; Lu et al., 2013a; Yang et al., 2015a,b; Zeng et al., 2017), lake sediments (e.g., Xiao et al., 2004; Chen et al., 2015; Wen et al., 2010; Zhou et al., 2016; Goldsmith et al., 2017), peat deposits (e.g., Hong et al., 2001; Zhou et al., 2010; Zhao et al., 2017), dune field deposits in northern China (e.g., Lu et al., 2005, 2011; Zhou et al., 2008, 2009; Mason et al., 2009; Yang et al., 2010; Xu et al., 2015), and speleothem oxygen isotope records (Yuan, 2004; Dykoski et al., 2005; Wang, 2005; Cheng et al., 2016). However, whether the Asian summer monsoon responds directly to precession-induced Northern Hemisphere summer insolation forcing on the orbital timescale with no phase lag (Yuan, 2004; Dykoski et al., 2005; Wang, 2005), or whether the response is significantly delayed by combined internal feedback forcings such as changes in precessiondriven sensible heating of the Northern Hemisphere, ice volume, and latent heating of the southern Indian Ocean (Clemens et al., 2010), has been intensively debated. Because of their precise ${ }^{230}$ Th dating and high resolution, stalagmite oxygen isotope records, which may reflect genuine changes in precipitation, are considered a reliable record of EASM. These records indicate that the EASM is directly driven by Northern Hemisphere summer insolation (Yuan, 2004; Dykoski et al., 2005; Wang, 2005). However, in recent years several studies have suggested that the oxygen isotope signal of stalagmites from China probably reflects changes in water vapor from the monsoon regions of the Indian Ocean and the Indian subcontinent, rather than local precipitation variations (Pausata et al., 2011). As a result, the mechanisms of the insolation-driven EASM have begun to be questioned, which hinders our understanding of EASM variability and limits our ability to predict future changes. Consequently, we need to obtain additional paleoclimatic records, based on unambiguous proxies and with absolute dating, from the zones influenced by the EASM.

In the semi-arid area of northern China (traditionally defined as the zone bounded by the 400 and $200 \mathrm{~mm}$ annual average isohyets, Fig. 1a), the sandy deserts include the Mu Us, Otindag, Horqin and Hulunbuir dune fields, which form an east-west trending belt in the mid-latitude interior, with a total area of about $13.65 \times 10^{4} \mathrm{~km}^{2}(\mathrm{Lu}$ et al., 2013b). These four dune fields are located at the northern edge of the temperate monsoon region in East Asia, and their precipitation is sensitive to changes in the strength of the EASM. The aeolian sand sandy paleosol sequence preserved in the stabilized and semi-stabilized sand dunes is an outstanding geological archive providing insights into past paleoclimatic and environmental changes in the region (Sun et al., 1998; Lu et al., 2005, 2011, 2013b; Mason et al., 2008; Zeng et al., 2013; Xu et al., 2015). Previous research on these sedimentary sequences has deepened our understanding of environmental changes within Chinese dune fields (e.g., Qiu et al., 1992; Wang, 1992; Sun et al., 1998, 2000). However, most of the early studies were limited by the dating techniques used and by an incomplete understanding of aeolian sedimentary processes. In recent years, with the rapid development of optically stimulated luminescence (OSL) dating, especially the application of the single aliquot regenerative (SAR) dose protocol, the precision and accuracy of the dating of aeolian sediments has dramatically improved (Wintle and Murray, 2006). Thus, recently, OSL dating has been widely used to study the environmental evolution of the dune fields in northern China (e.g., Li et al., 2002, 2012; Lu et al., 2005, 2011; Li and Sun, 2006; Zhou et al., 2008, 2009; Mason et al., 2009; He et al., 2010; Yang et al., 2010, 2010, 2015a,b; Yang and Ding, 2013; Xu et al., 2015). In addition, the compilation of a large number of independent OSL ages from various sections can be used to generate chronological database, from which we can further explore the processes of dune stabilization/activation, and the factors driving past variations in effective moisture (Lu et al., 2005; Mason et al., 2009).

Hulunbuir dune field was an important area of animal husbandry in China. However, climate change, over-intensive cultivation and livestock overgrazing have resulted in intense aeolian activity and severe vegetation and soil degradation of the grassland. Remote sensing monitoring in 2006 indicated that the total area of desertified land in Hulunbuir dune field was $3859.6 \mathrm{~km}^{2}$, of which $1359.4 \mathrm{~km}^{2}$ were severely desertified (Guo et al., 2010). Several early studies were conducted on the paleoclimate record of the Hulunbuir dune field. Wang (1992) used a radiocarbon-dated pollen record from sandy paleosol to reveal that since the early Holocene the Hulunbuir dune field have experienced four stages of stability (1.2-9 ka, 6-5 ka, 3.4-2.5 ka, and at $\sim 1 \mathrm{ka}$ ) and intervals of reactivation (9-6 ka, 5-3.4 ka, 2.5-1.2 ka, $1-0 \mathrm{ka}$ ). However, radiocarbon dating of the sandy paleosol is problematic because of the low organic carbon content and possible carbon contamination from the roots of modern vegetation. Li and Sun (2006) applied OSL dating to three sections, which indicated that the $\mathrm{Hu}$ lunbuir dune field was mainly stable and undergoing strong soil development from 11-4.4 ka, and that the climate generally became arid after $4.4 \mathrm{ka}$; however, the arid interval was interrupted by three phases of weak soil development at $1.8-1.4,1.2-1.0$ and $0.84-0.5 \mathrm{ka}$. These findings support the hypothesis of direct forcing of the EASM by variations in Northern Hemisphere summer insolation. Yang and Ding (2013) conducted OSL dating and measurements of environmental proxies from 13 sections in Hulunbuir dune field. The results revealed that the extent of the active sand dunes during the lateglacial was ten times than that of today, and that the sand dunes were stabilized by vegetation cover between 10-5 ka. However, compared to the intensive investigation of the Horqin, Otindag and Mu Us dune fields, research on the environmental evolution of the Hulunbuir sand dunes since the last deglaciation is limited, and the preliminary conclusions are controversial. In addition, due to the small number and uneven distribution of the studied sections, and the limited number of OSL ages, it is difficult to establish statistically significant chronological database of aeolian sand in the Hulunbuir dune field. The problem is compounded by the widespread occurrence of erosional hiatuses resulting from the high mobility of the sand dunes. Thus, more research is needed to determine the record of dry/humid oscillations in the Hulunbuir dune field.

In the present study, we conducted a detailed field investigation and OSL dating ( $\mathrm{n}=76$ dates) of 13 representative sections containing multiple layers of sandy paleosol from Hulunbuir dune field (Fig. 1b). We combined the dating results with measurements of environmental proxies (grain size and magnetic susceptibility, MS) and previously published OSL dates $(n=49)$ to generate new chronological database and records of aeolian activity for the fossil dunes in Hulunbuir dune 

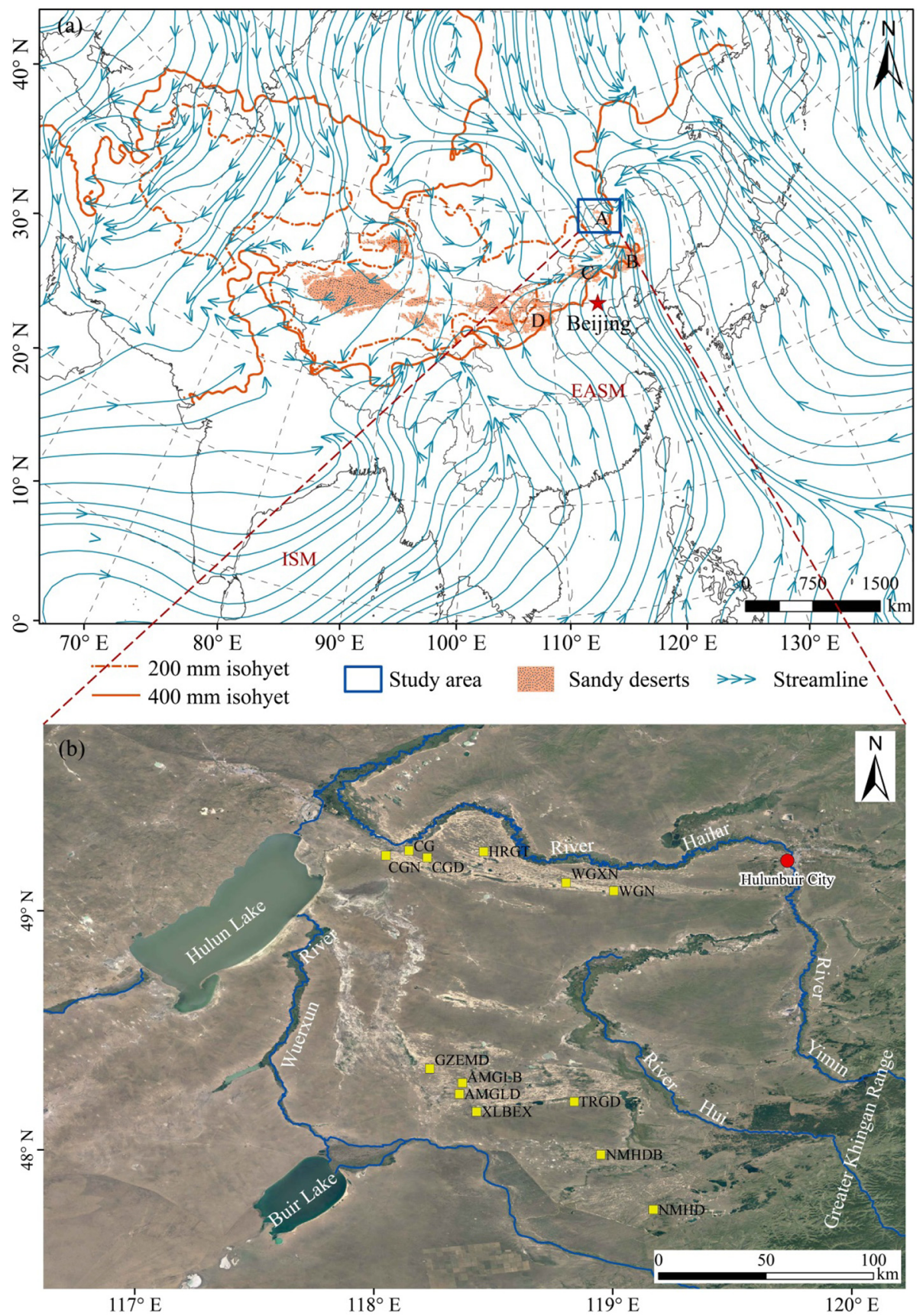

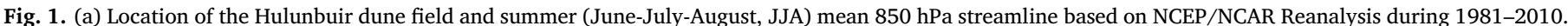

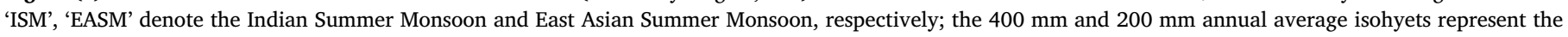

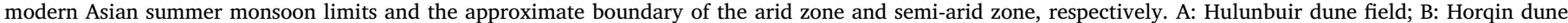
field; C, Otindag dune field; D, Mu Us dune field. (b) Locations of the investigated sections shown by solid yellow squares.

field. Finally, based on an extensive comparison of our new record of dune activity from Hulunbuir dune field and other EASM records with time series of potential forcing factors, we further discuss the mechanisms and processes involved in the response of dune activity and pedogenesis to changes in monsoon precipitation and human activity since the last deglaciation.

\section{Study area and methods}

\subsection{Study area}

The Hulunbuir dune field is located on the Inner-Mongolian Plateau, along the wester margin of the Greater Khingan Range (Fig. 1b). From a tectonic geomorphological perspective, the north, east and west parts lie within the Hailar Basin which is surrounded by low mountains and hills mainly composed of Jurassic igneous rocks (Qiu, 2008). To the south is the national boundary between the People's Republic of China and Mongolia. The terrain in the interior of the basin is relatively flat, and the basin is filled by a thick sequence of Mesozoic and Cenozoic sedimentary strata (Qiu, 2008). The top of the Hailar Formation, which was formed during the late Pleistocene and Holocene, is a sequence of alluvial-lacustrine-aeolian sediments mainly consisting of medium- and fine- sand, silt and clay, with small amounts of coarse sand and gravel (Zhang et al., 2006; Qiu, 2008). These weakly-consolidated sandy sediments are prone to erosion and transformation to aeolian sand because of abrasion and deflation by strong winds. Thus, they are the 
primary material source of the Hulunbuir dune field. The interior of Hailar Basin contains numerous rivers, lakes, and swamps. The principal rivers are the Wuerxun River, Kelulun River and Hailar River, and the latter's tributaries, the Yimin River and Hui River (Fig. 1b). There are more than 400 lakes in the Hailar Basin, more than 50 of which have areas exceeding $1 \mathrm{~km}^{2}$ (Wu, 2009). The largest is Hulun Lake with a total area of $2339 \mathrm{~km}^{2}$; it is located in the northwestern part of the sand dune area; and the second largest is Buir Lake with a total area $609 \mathrm{~km}^{2}$, located in the southwestern part of the sand dunes area $\mathrm{CWu}$, 2009; Wen et al., 2010). The modern dune field is mainly distributed on the high plain between the Yimin and Wuerxun Rivers, and it can be divided into two sand zones: north and south. The northern sand zone is located on the south bank of the Hailar River, and its distribution is relatively continuous, while the southern sand zone is mainly composed of four spatially independent desert areas. In addition, there is an area of sand dunes in the eastern coastal area of Hulun Lake (Fig. 1b). The regional climate is mainly influenced by the East Asian monsoon and the westerlies. During summer, warm moist air masses from the west side of the Subtropical High in the western Pacific interact with cold air masses from northern high latitudes, which produces most of the annual precipitation in the area. During winter, the prevailing wind direction is northwesterly, generated by the Siberian-Mongolian High, and the weather is cold, dry and snowy. Meteorological observations show that the annual average temperature in the region ranges from $-1.0^{\circ} \mathrm{C}$ to $-2.2{ }^{\circ} \mathrm{C}$; the average temperature in January ranges from $-26^{\circ} \mathrm{C}$ to $-29^{\circ} \mathrm{C}$; the average temperature in July ranges from $20^{\circ} \mathrm{C}$ to $21^{\circ} \mathrm{C}$; and the average annual precipitation ranges from $430 \mathrm{~mm}$ in the southeast to $250 \mathrm{~mm}$ in the northwest. The number of annual gale days with wind speeds above $5 \mathrm{~m} / \mathrm{s}$ is $140-240$; in particular, the number of gale days with wind speeds exceeding $17.5 \mathrm{~m} / \mathrm{s}$ is up to 15 during April and May, which frequently results in severe dust storms and large amounts of suspended dust in the atmosphere (Jin et al., 2011).

\subsection{Field investigations and sections}

Field investigations and sampling were carried out across the Hulunbuir dune field during July 2011. We found that the grassland landscape had been largely destroyed by wind erosion and intensified human activity, which had resulted in numerous blowouts on the land surface (Fig. 2e). The modern sand dunes have mainly accumulated around the blowouts which are a continuous source of aeolian sand. The stabilized and semi-stabilized honeycomb dunes, nabkhas dunes and sand sheets are the major aeolian landforms (Fig. 2f), while mobile dunes are much less common because of recent engineering projects conducted by the local government to fix the dunes. The outcrops commonly contain 2-3 layers of buried sandy paleosol (Fig. 2a-d) and in several sections, even five buried sandy paleosol layers were found. We investigated a total of 13 aeolian sand - sandy paleosol section, of which 6 sections are in the northern sand zone and 7 sections are in the southern sand zone (Fig. 1b). The geomorphological contexts of these sections were classified as wind-erosion unaka, stabilized dunes and blowouts (Fig. 2e). The sections consist of light brown sand layers interbedded with gray sandy weakly-developed paleosol or dark gray sandy paleosol. The texture is mainly medium- or fine- sand. Soils were identified by dark-colored buried A horizons and other pedogenic features such as insect burrows. The bases of the sections are underlain by older aeolian sand deposits (the bases were not seen) while the tops are mainly mantled with modern aeolian sand deposits. However, in the lower part of the HRGT and AMGLD sections there is a 20 to $30-\mathrm{cm}$ thick layer of brown sandy paleosol, and in the lower part of the CG section there is a 150-cm-thick layer of black sandy paleosol with a high organic matter content (the total organic carbon content reaches up to 6.3\%; Fig. 2c-d, Fig. 3). After careful observation of the sedimentary structures and landform characteristics of the outcrops, the 30 to 50$\mathrm{cm}$-thick surface sediment layer was removed with a shovel to clean the vertical sections. Then, pits at the bases were excavated at the bottom of the outcrops to expose the underlying aeolian sand. Samples for OSL dating were obtained by hammering stainless steel tubes into the vertical sections. The tubes were packed in black plastic bags and immediately sealed with adhesive tape to prevent light exposure and moisture loss. Apart from the NMHDB section, from which bulk samples were collected at each OSL sampling position (Fig. 3), all other sections were collected at 10-cm intervals for MS and grain-size measurements. A total of 76 OSL samples and 339 bulk samples were collected from the 13 sections.

\subsection{Laboratory measurements}

All the OSL samples were pretreated and measured under the subdued red light conditions. In the laboratory, about 3-5 $\mathrm{cm}$ of material at each end of the tube was scraped out and used to determine the water content and concentrations of uranium (U), thorium (Th) and potassium $(K)$, and the middle part was used for equivalent dose $\left(D_{e}\right)$ determination. Samples were wet sieved to extract the $90-150 \mu \mathrm{m}$ fraction, treated with $10 \% \mathrm{HCl}$ and $30 \% \mathrm{H}_{2} \mathrm{O}_{2}$ to remove carbonate and organic matter, respectively, and then with $40 \% \mathrm{HF}$ for $40 \mathrm{~min}$ to remove feldspar grains. The purity of the quartz was determined using the OSL-IR depletion ratio method (Duller, 2003). Then, the isolated quartz grains were mounted as large $(\sim 8 \mathrm{~mm})$ aliquots on stainless steel discs and measured on a Risø TL/OSL-DA-20C/D reader fitted with blue diodes $(\lambda=470 \pm 30 \mathrm{~nm})$ and IR-LEDs $(\lambda=870 \pm 80 \mathrm{~nm})$. The OSL signal was detected by a 9235QA photomultiplier tube through a $7.5 \mathrm{~mm}$ thick of Schott U-340 filter (Bøtter-Jensen et al., 2010). The $D_{e}$ was determined using the SAR protocol (Murray and Wintle, 2000, 2003) with a preheat of $260^{\circ} \mathrm{C}(10 \mathrm{~s})$ and cut-heat of $220^{\circ} \mathrm{C}$ combination based on the preheat plateau and dose recovery tests, which were considered the stringent checks for the OSL measurement on representative samples (Fig. S1). Aliquots yielding recycling ratios differing from unity by greater than $10 \%$ or recuperation values higher than $5 \%$ were removed for final $D_{e}$ calculation. The environmental dose rate was calculated from $\mathrm{U}, \mathrm{TH}$ and $\mathrm{K}$ concentrations measured by neutron activation analysis (NAA).Water content (mass of moisture/dry mass) was determined by weighing the sample before and after drying with $\pm 10 \%$ uncertainties. Using the revised dose-rate conversion factors and water content attenuation factor (Aitken, 1998), the elemental concentration was converted to effective dose rate. The calculation was performed using the 'AGE' program of Grün (2009), including a calculation of the cosmic ray contribution to the dose rate.

Low field-magnetic susceptibility $(470 \mathrm{~Hz})$ was measured using a Bartington Instruments MS2 magnetic susceptibility meter with a MS2B sensor. Samples of $10 \mathrm{~g}$ mass were used, which were prepared by drying at a temperature below $40{ }^{\circ} \mathrm{C}$. The values were normalized by the sample mass to obtain the mass-specific MS.

The grain-size distribution was determined using a Malvern Mastersizer 2000 laser particle-size analyzer with a measurement range of $0.02-2000 \mu \mathrm{m}$ and a relative error of less than $2 \%$. The pre-treatment procedure consisted of the removal of organic matter and secondary carbonates by the addition of $10 \% \mathrm{H}_{2} \mathrm{O}_{2}$ and $10 \% \mathrm{HCl}$, respectively, followed by dispersal using $10 \mathrm{ml}$ of $0.05 \mathrm{~mol} / \mathrm{L}\left(\mathrm{NaPO}_{3}\right)_{6}$ and treatment in an ultrasonic vibrator for $10 \mathrm{~min}$ (Lu and An, 1997). Grain-size statistics were calculated using the GRADISTAT (v8.0) program developed by Blott and Pye (2001), and grain-size parameters were calculated by the Folk and Ward (1957) graphical method. The Udden Wentworth grade scale (Udden, 1914; Wentworth, 1922) was adopted as the grain-size scale, where the grade scale boundaries are logarithmically transformed to phi $(\phi)$ values, using the expression $\phi=\log _{2}{ }^{\mathrm{d}}(\mathrm{d}$ is the grain diameter in $\mathrm{mm}$ ). All the above laboratory measurements, except the dose rate, were carried out at the Geomorphology Process Laboratory of the School of Geography and Ocean Science, Nanjing University. 


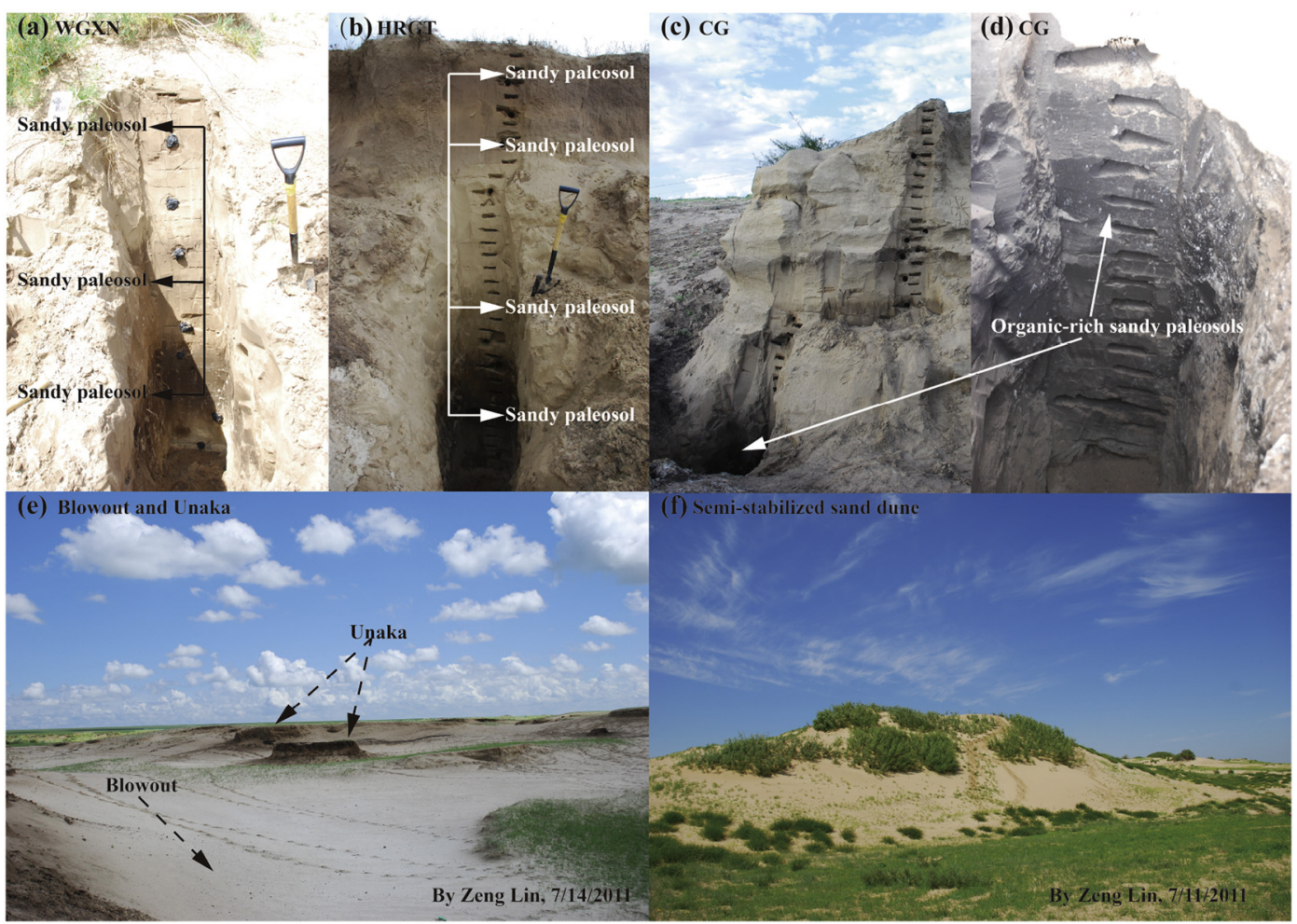

Fig. 2. Photograph of the outcrops and sampling pits excavated at the base of typical sections (a-d), and the typical landscape of the Hulunbuir dune field (e-f).

\subsection{Error-incorporated Gaussian probability density}

A probability density (PD) approach, incorporating the measurement errors for the OSL age cluster, was used to determine the center of the age distribution, based on the PD peak. In this study, the PD was calculated using Matlab programming scripts based on the
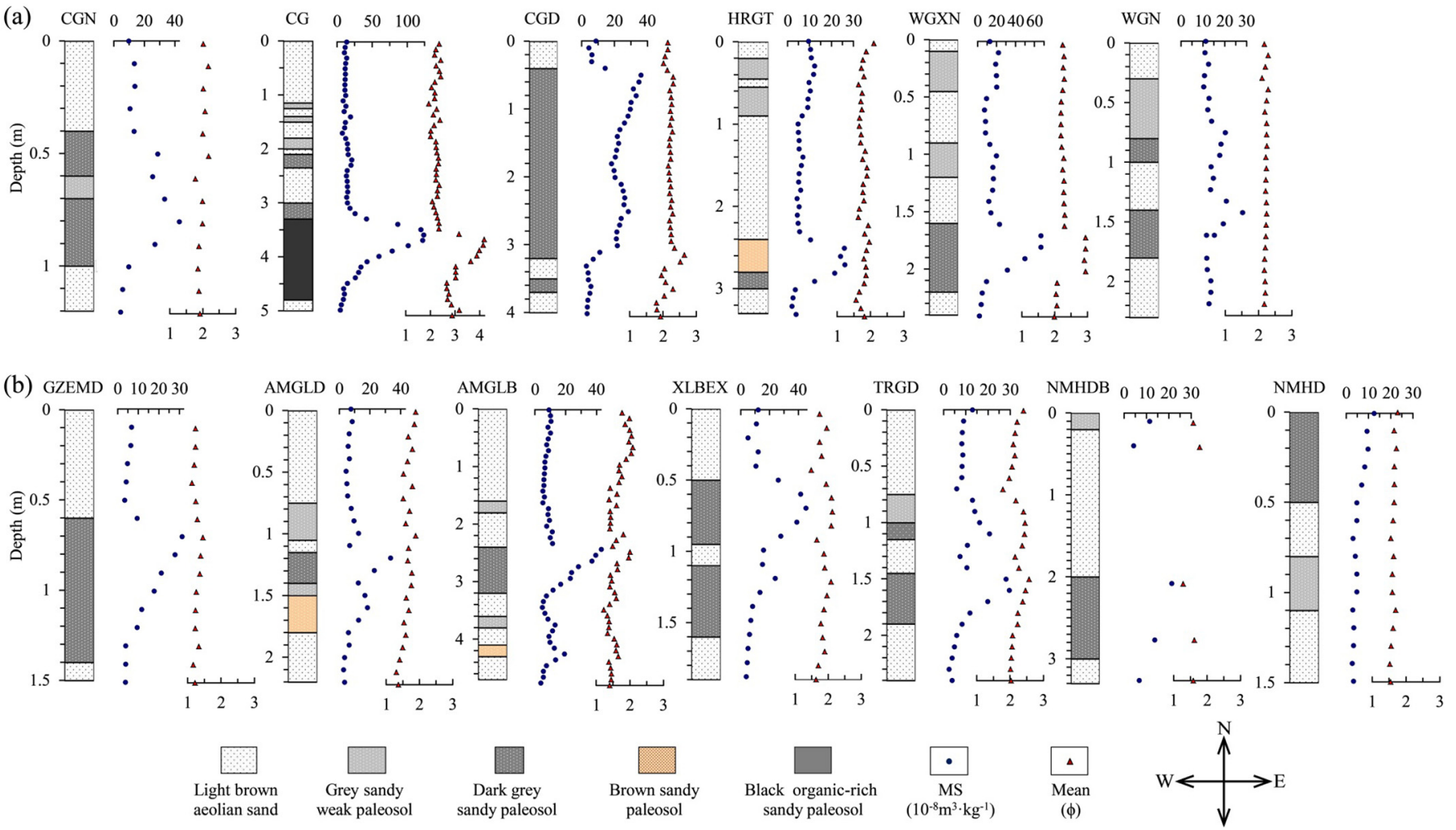

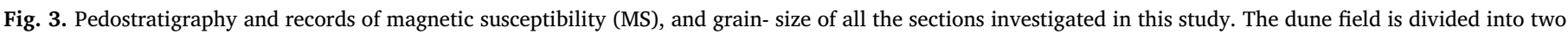

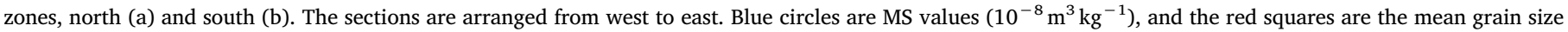
(ф). 
algorithm of Venkatesan and Ramesh (1993). The detailed descriptions of this method are given in the supplementary materials.

\section{Results and discussion}

\subsection{Grain size and MS characteristics of the sections and their implications for pedogenesis}

The grain-size distribution is a fundamental physical property of clastic sediments and it is affected by sediment source, transport conditions, the sedimentary environment and post-depositional pedogenesis (Visher, 1969). Grain-size parameters and the grain-size distributions of sediments can provide insights into depositional processes and dynamics and material sources and thus they can be used to determine the type of and changes in the sedimentary environment (e.g., Folk and Ward, 1957; Visher, 1969; Folk, 1971; Lancaster, 1981; Livingstone et al., 1999; Ding et al., 2001; Purkait, 2010). The grain-size distribution data and related statistical parameters of all samples in this study are listed in Table S3. The logarithmic frequency curves of the grainsize distributions show that almost all the samples from the aeolian sand and sandy paleosol have a unimodal distribution, except for the organic-rich sandy paleosol in the CG section which has a bimodal distribution (Fig. 4a). Because none of the samples contain gravel, triangular diagrams with sand (-1-4 $\phi)$, silt $(4-9 \phi)$ and clay $(<9 \phi)$ as the end members can be used to illustrate the sediment components and textural classification (Folk et al., 1970). Reference to Fig. 4b shows that the sand content of all the aeolian sand and most of the sandy paleosol exceeds $90 \%$ (hence the textural classification is sand), while the silt content of part of the sandy paleosol is $10-20 \%$, and that of the organic-rich sandy paleosol is $15-35 \%$ (hence the textural classification is silty sand). The aeolian sand generally contain no clay. The clay content of the sandy paleosol is generally less than $2 \%$, while that of the organic-rich sandy paleosol is $2-6 \%$. Thus, the sandy paleosol and organic-rich sandy paleosol have a higher clay content than the aeolian sand, and hence a finer mean grain size ( $\phi)$. In addition, the mean grain size of the paleosol generally exhibits a well-defined peak, the amplitude of which depends on the degree of pedogenesis (Fig. 3). Fig. S2 shows a box plot of the grain-size parameters categorized as aeolian sand, sandy paleosol, and organic-rich sandy paleosol. The plots show that the mean grain size of all the aeolian sand and sandy paleosol is in the medium-fine-sand range (1-3 $\phi)$, while that of the organic-rich sandy paleosol in the CG section is in the very fine sand-very coarse silt range (3-5 $\phi)$. Thus, the mean grain size of the aeolian sand (1.88 $\phi)$ and sandy paleosol (2.01 $\phi)$ of the Hulunbuir dune field is within the range of variation of deserts elsewhere in China and worldwide (Zhu et al., 2014). Although their mean grain size is roughly comparable to that of the Mu Us dune field, the Otindag dune field and the Horqin dune field in northern China (Shen et al., 2016), it is coarser than that of the the Taklimakan Desert (Zhu et al., 2014), Badan Jaran Desert (Zhu et al., 2014), Namib Desert (Lancaster, 1981), Thar Desert (Purkait, 2010) and Simpson Desert (Folk, 1971), which are dominated by mobile dunes composed of fine sand-very fine sand (2-4 $\phi)$. We suggest that the coarser aeolian sand in the stabilized and semi-stabilized dunes can be attributed mainly to the relatively brief transport time and short transport distance because of the denser vegetation coverage compared to the mobile dunes.

The average sorting and skewness coefficients of the aeolian sand are 0.682 and 0.070 , respectively (Fig. S2); these values indicate that the aeolian sand is moderately well sorted with a symmetrical distribution, following Folk and Ward (1957). However, with strengthening pedogenesis both the sorting and skewness coefficients of the sandy paleosol and organic-rich sandy paleosol increase, indicating poorer sorting and a positive skewness. In addition, the average kurtosis value (1.001) of the aeolian sand is classed as mesokurtic, while those
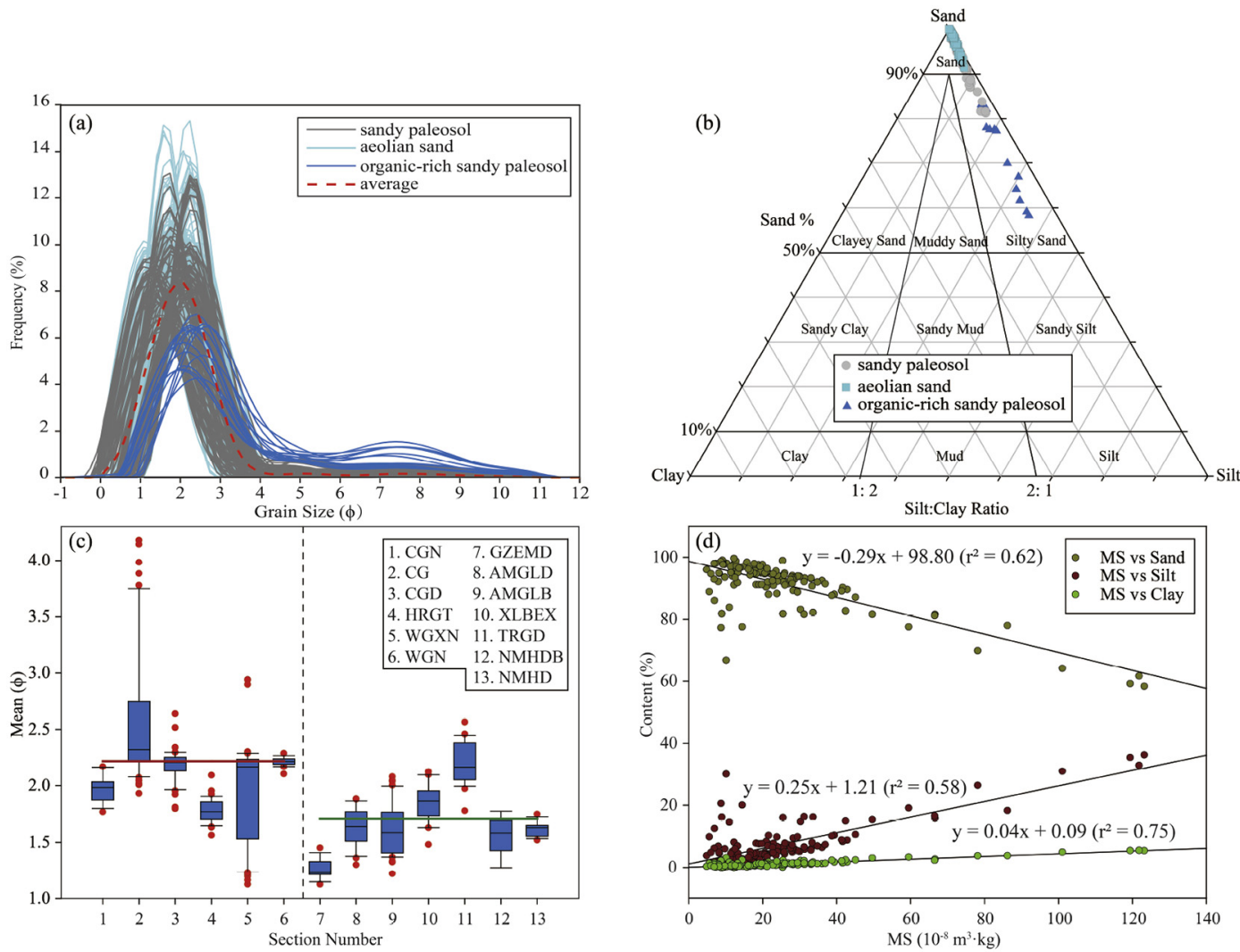

Fig. 4. Logarithmic frequency curves of grain-size fractions (a), triangular diagrams illustrated the texture classification (b), box plots of mean grain size (c), and biplots of magnetic susceptibility (MS) versus the sand, silt and clay contents (d) of all the samples used in this study. The dashed line in subplot 'c' separates sections from the northern sand zone (left) from those from the southern sand zone (right). 
of the sandy paleosol and organic-rich sandy paleosol are classed as leptokurtic and very leptokurtic, respectively, according to Folk and Ward (1957).

Many studies have suggested that the grain-size distribution of aeolian sand is generally unimodal, and that the medium sand and fine sand-very-fine sand have mean grain sizes from 1-4 $\phi$, and are moderately sorted to moderately well-sorted, positively skewed and mesokurtic-leptokurtic-very leptokurtic (e.g., Folk, 1971; Goudie et al., 1973; Lancaster, 1981; Wang et al., 2003; Zhu et al., 2014). Therefore, the grain-size results indicate that the sand layers of the Hulunbuir dune field are composed of typical wind-sorted aeolian sand. However, the sandy paleosol and organic-rich sandy paleosol have a higher silt and clay content and thus a finer mean grain size imparted by postdepositional processes. When the monsoon precipitation increased, the mobile dunes would become stabilized and semi-stabilized and colonized by vegetation. The resulting vegetation cover would significantly reduce the intensity of wind erosion and trap airborne dust particles. Furthermore, the formation of humus from plant residues could enhance the adsorption capacity of the soil for fine particles (Yaalon and Ganor, 1973; Mason and Jacobs, 1998). The organic-rich sandy paleosollikely developed in the inter-dune lowland areas, and been subject to seasonal waterlogging during humid intervals. The relatively high moisture content would also have facilitated the accumulation of organic matter and retention of deposited atmospheric dust. Therefore, changes in the grain size of the sandy sediments are likely to reflect changes in regional effective humidity and the strength of pedogenesis.

A box plot of the mean grain size of the 13 studied sections (Fig. 4c) reveals significant spatial differences: the northern sand zone (mean grain size of $2.22 \phi$ ) is significantly finer-grained than the southern sand zone (mean grain-size of $1.71 \phi$ ), which is likely related to provenance. The aeolian sand in the Hulunbuir dune field is derived from the fluvial-lacustrine sediments from the uppermost strata of the basin (Zhang et al., 2006). The rivers mainly rise in the Greater Higgnan Mountains on the eastern side of the Hulunbuir Basin (Fig. 2b), and the grain size of the fluvial sediments will become finer with increasing distance downstream because of the reduced transport capability. The southern sand zone is located closer to the upper reaches of the rivers and therefore the aeolian sand is coarser-grained.

The MS is the degree to which a material can be magnetized in an external magnetic field, and its value is related to the type, content and grain size of the magnetic minerals (Thompson and Oldfield, 1986). Box plots of the MS values of aeolian sand, sandy paleosol, and organic-rich sandy paleosol are illustrated in Fig. S3. The average MS values of the three sediment types are 8.36, 21.07 and 57.55, respectively, and thus their magnetic mineral content increases with increasing pedogenesis. The MS values of the aeolian sand are relatively constant with depth within the sections, with minor fluctuations, while the sandy paleosol and organic-rich sandy paleosol are characterized by peaks of varying amplitude (Fig. 3). In addition, the MS of the dark gray sandy paleosol and brown sandy paleosol is significantly higher than that of the grey sandy weak paleosol in the same section (Fig. 3).

Overall, the foregoing indicates that the MS of soil horizons is positively correlated with the intensity of soil formation. In recent years, much research has suggested that the soil MS is mainly related to the level of precipitation/soil effective moisture (Zhou et al., 1990; Zheng et al., 1991; Hao et al., 2008; Oldfield et al., 2009). The analysis of the relationship between the MS of a global distribution of soil samples and precipitation by Balsam et al. (2011) indicated that MS increased with increasing rainfall from about $200 \mathrm{~mm} / \mathrm{yr}$ to $1000-1200 \mathrm{~mm} / \mathrm{yr}$. Notably, detailed rock magnetic studies of the loess-paleosol sequence show that the enhanced MS of paleosol was caused by the in situ production of fine-grained magnetite and maghemite particles during pedogenesis (e.g., Zhou et al., 1990; Zheng et al., 1991; Liu et al., 1992; Maher, 1998). Thus, we speculate that the MS variations of the aeolian sand-sandy paleosol sequence in the Hulunbuir dune field are probably related to the intensity of pedogenesis. However, it is noteworthy that the MS of the sandy paleosol is negatively correlated with the sand content and positively correlated with the silt and clay content (Fig. 4d). The coefficient of determination $\left(r^{2}\right)$ of the linear relationship between MS and clay content is $\sim 0.75$ indicating a relatively strong correlation. Thus, the allochthonous input of silt and clay particles may contribute part of the ferrimagnetic component during pedogenesis, due to the likelihood that soil formation is limited by the poor hydrothermal conditions in Hulunbuir dune field.

In summary, both the grain-size distribution and the MS of the Hulunbuir dune field are correlated with the degree of pedogenesis; specifically, the paleosol has a finer grain size and higher MS, while the aeolian sand has a coarser grain size and lower MS. However, it appears that the MS is more sensitive to pedogenesis than the grain size because the MS profiles exhibit greater variability (Fig. 3).

\subsection{Distribution of the OSL ages and its implications for paleoclimatic interpretation}

All the OSL dating results are listed in Table S1. Most of the samples showed similar luminescence characteristics and the normal distributions for the $D_{e}$ values, suggesting that the sand grains were well bleached prior to deposition (Fig. S1). Finally, total 76 OSL ages from 13 sections in the Hulunbuir dune field were obtained in this study (Fig. 5, Table S1). We combined these ages with 49 previously reported OSL ages which have the similar measurement criterion (Li et al., 2002; Li and Sun, 2006; Yang and Ding, 2013) to create a new chronological database for the aeolian sand $(n=65)$ and paleosol $(n=60)$ of the Hulunbuir dune field. The age ranges of the aeolian sand and paleosol are $18.07-0.04 \mathrm{ka}$ and $15.44-0.04 \mathrm{ka}$, respectively. Histograms of the frequency distribution of the ages, ranked plots (cumulative totals in ascending order) and the PD plot of the OSL ages during the past $18 \mathrm{ka}$ are illustrated in Fig. 6. The OSL age distributions of the aeolian sand and paleosol are very similar, and can be divided into four stages:

Stage 1 (18-16 ka). There is only two OSL age for this interval, from aeolian sand.

Stage $2(16-9 \mathrm{ka})$. There are 44 ages in this stage, with a single peak in the PD curves of both aeolian sand $(\sim 13.5 \mathrm{ka})$ and paleosol $(\sim 11 \mathrm{ka})$.

Stage $3(9-5 \mathrm{ka})$. There are only 10 ages for this stage. The PD values for aeolian sand and paleosol both exhibit minima at $\sim 6 \mathrm{ka}$. In addition, there is an age hiatus for paleosol during 7-5 ka, and there is almost a complete absence of OSL ages for aeolian sand during 9-5 ka in addition to one at $\sim 7 \mathrm{ka}$.

Stage 4 (5-0 ka). There are 72 ages for this stage. There is a major peak in the PD curves of both aeolian sand and paleosol around $1.0 \mathrm{ka}$.

The mains characteristics of the distribution of OSL ages can be summarized as follows: First, the OSL age distributions of the aeolian sand and paleosol are very similar. Second, the OSL ages at the base of the sections are concentrated during the interval from the last deglaciation to the early Holocene (16-9 ka), while there is an almost a complete absence of OSL ages of aeolian sand corresponding to the Last Glacial Maximum (LGM). Third, there is a lack of OSL ages for paleosol during the Holocene Optimum (HO, 9-5 ka). Fourth, the OSL ages of the aeolian sand and paleosol are both biased towards the recent period, with ages less 1 ka having the highest frequency of occurrence.

Several studies have shown that the climate in the northern Chinese dune fields during the LGM was cold (sub-zero temperatures) and dry which resulted in a very sparse vegetation cover, widespread dune mobility and a great expansion of the area of dune fields ( $\mathrm{Lu}$ et al., 2011, 2013b; Xu et al., 2015). However, there is scarcity of OSL ages for the Hulunbuir dune field corresponding to the LGM. This phenomenon is characteristic of the northern Chinese dune fields (Lu et al., 2013b; Xu et al., 2015) and of mid-latitude deserts elsewhere, such as in the dunefields of southwestern Africa, the European sand belt and the Central Great Plains, USA (Telfer and Thomas, 2007; Stone and Thomas, 2008; Xu et al., 2015). Various explanations have proposed to explain this paucity of sands of LGM age. They include factors based on 

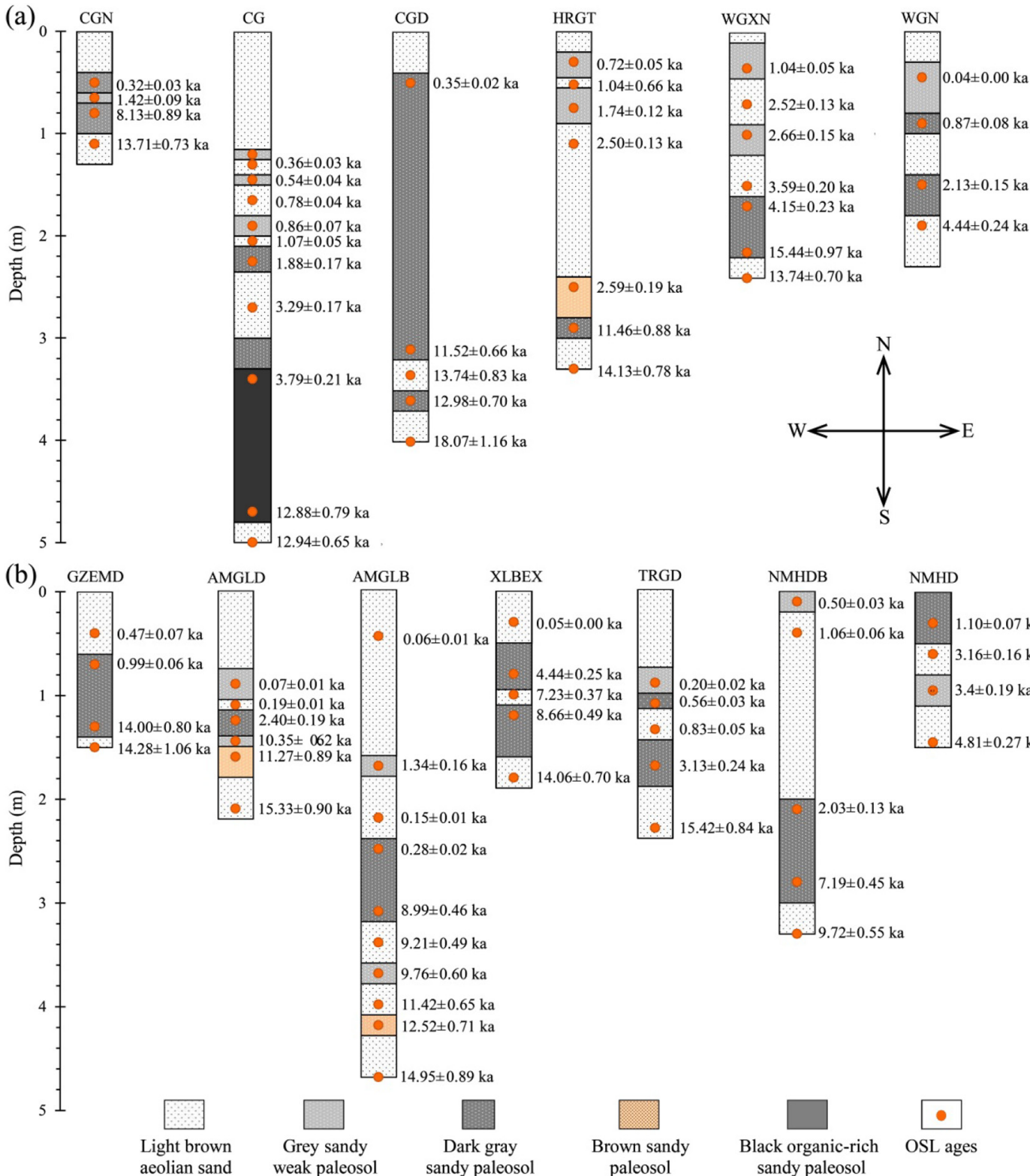

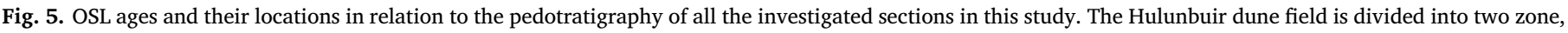
north (a) and south (b). The sections are arranged from west to east.

site-specific landforms and climatic conditions, such as surficial re-sedimentation of particles by rain or snowmelt on top of impervious permafrost resulting in poor preservation of aeolian sediments in the case of the European sand belt during LGM (Kasse, 1997); reworking by subsequent aeolian activity or bioturbation (Halfen et al., 2012); and inadequate or biased sampling strategies (Telfer and Thomas, 2007; Stone and Thomas, 2008). However, a potentially more plausible interpretation was proposed which suggested that net accumulation was limited by the intensive aeolian activity during the LGM (Lu et al., 2013b; Xu et al., 2015): due to the prevailing strong winds and cold and dry climate during the LGM, the aeolian sand would have been continuously recycled. OSL dating can only reveal the age of the most recent exposure (Aitken, 1998) and quartz grains could not accumulate a luminescence signal until the aeolian sand was buried to a sufficient depth, when the climate became warmer and more humid during the last deglaciation. However, we suggest that there were at least two additional factors which may be responsible for the limited number of LGM OSL ages of aeolian sand: First, the widely developed permafrost in northern Chinese dune fields could have caused the surface sediments to remain frozen, which would have reduced the supply of deflated sand and led to the limited formation of mobile dunes; and second, many researchers in China have ignored the fact that their sampling sections were usually natural outcrops or excavated pits with a depth of $\sim 1-2 \mathrm{~m}$, and thus the base of the aeolian sand was not completely exposed in most of these sections. However, in recent years augering equipment has been used to obtain deeper buried aeolian sand, many of which had been dated back to the late Pleistocene by OSL dating (Telfer and Hesse, 2013). Therefore, to further investigate the actual mechanism responsible for the scarcity of aeolian sand during LGM in the northern Chinese dune fields, drilling techniques should be applied to obtain more deeply buried aeolian sand samples for OSL dating.

The similarity of the OSL age distributions of the aeolian sand and paleosol in Hulunbuir dune field is contrary to the assumed conceptual model of surface processes in the dune fields. It was generally accepted that dune mobility and soil development proceeded in opposition: i.e., that during warm and humid periods the vegetation cover increased and soils developed rapidly, which led to reduced dune mobility. In 


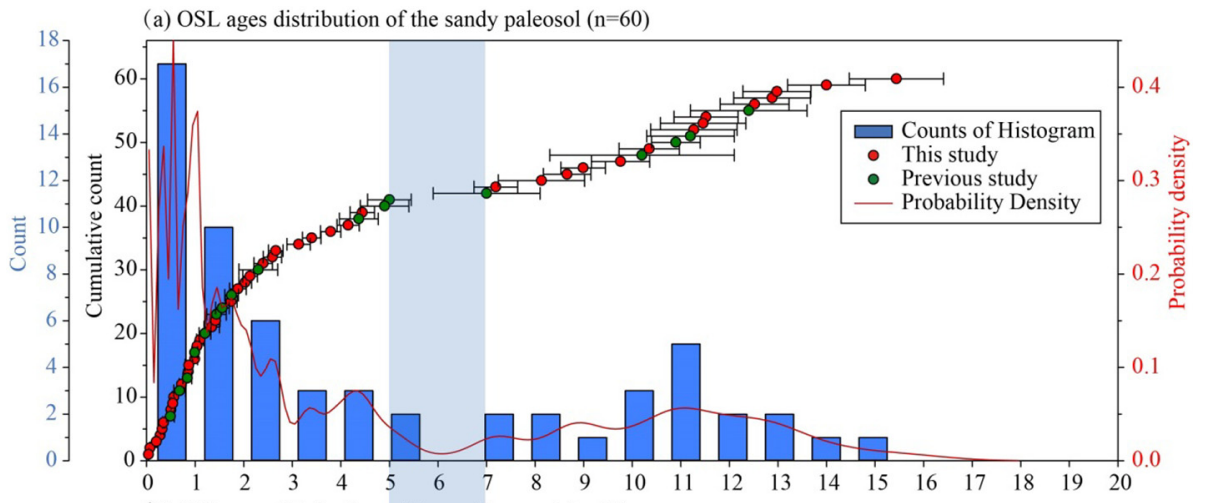

(b) OSL ages distribution of the aeolian sand $(n=65)$

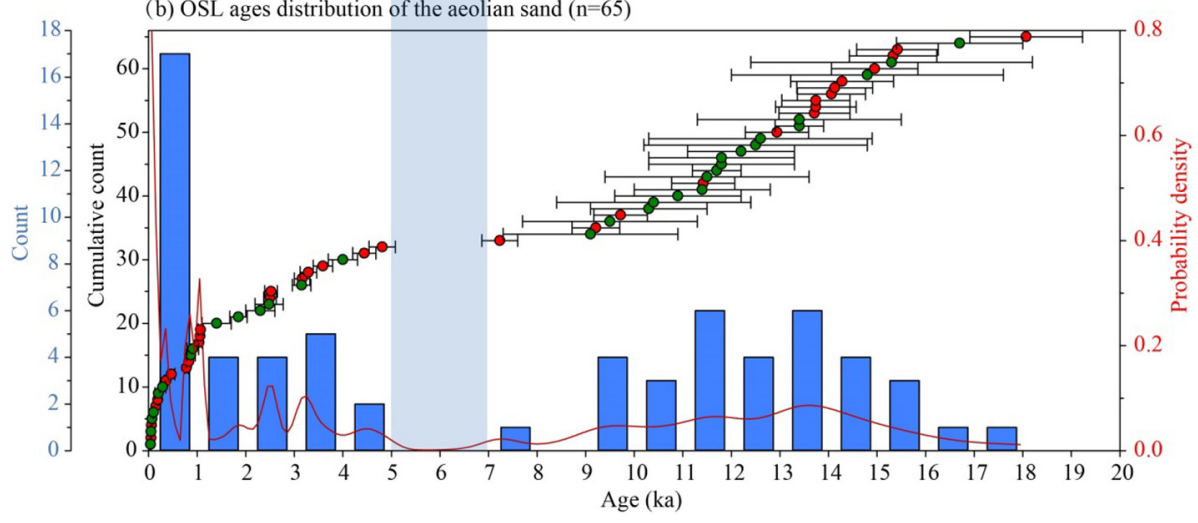

Fig. 6. OSL age distributions versus time of sandy paleosol (a) and aeolian sand (b) in Hulunbuir dune field, illustrated by probability density (PD) plot, histograms of frequency distribution and ranked plots (cumulative counts in ascending order) of the OSL ages. Blue shading indicates an OSL age hiatus in both aeolian sand and paleosol during 5-7 ka. contrast, during cold and dry periods, the vegetation cover decreased and sand dunes would be reactivated which reduced soil development (Lu et al., 2005). Thus, according to the widely accepted paleoclimate interpretation, the cluster of OSL ages from the aeolian sand represents periods of widespread and intensive aeolian activity (Lu et al., 2005; Zhou et al., 2008; Mason et al., 2009), which would led to the scarcity or complete absence of OSL ages of paleosol. However, the OSL ages of the paleosol in the Hulunbuir dune also exhibit a peak during the last deglaciation (Fig. 6). Furthermore, OSL ages of both aeolian sand and palaeosol are absent during the interval from 7-5 ka (Fig. 6). Thus, the similarity of the distributions of OSL ages of aeolian sand and paleosol presents a new challenge to their paleoclimatic interpretation.

A novel view is that the cluster of OSL ages from buried aeolian sand actually represents the time of dune field stabilization or a shift in dune field activity towards stabilization, rather than a maximum in the extent of dune activity, because of the continuous recycling of sand (Chase and Thomas, 2006; Chase, 2009; Xu et al., 2017). However, despite the cluster of OSL ages probably being biased towards the younger part of an extended period of dune activity, we still believe it is more plausible to interpret the OSL age clusters of the aeolian sand as an indicator of dune activity because of the slow turnover of the sand dunes associated with the mosaic-like vegetation distribution in the semi-arid dunefields, and that the compilation of OSL data from many sections enables the reconstruction of dune activity (Lu et al., 2011).

Several researchers have suggested that the paleoclimatic interpretation of the OSL ages of paleosol is a much more complex than that of aeolian sand, because the ages of the former may represent the age at the time of deposition of the parent material, or that the ages are distorted by aeolian processes or bioturbation (Mason et al., 2009; Lu et al. 2011). For example, some of the OSL ages from the paleosol are only slightly younger than the ages of the underlying aeolian sand, and thus they may represent the deposition age of the soil parent material just before dune stabilization, or they are a maximum age estimate of pedogenesis (e.g., the OSL age within the paleosol at site GZEMD; Fig. 5). In addition, the OSL ages from the top of thick paleosol are several thousand years, or even $\sim 10$ thousand years, younger than the ages near the base (e.g., the OSL ages within the paleosol at sites CG, CGD, WGXN, WGN, GZEMD, AMGLB, XLBEX and NMHDB; Fig. 5). This implies either that the sediment was slowly incorporated into the soil as it developed, or that contamination of younger grains into the unit sampled occurred as a result of bioturbation (Goble et al., 2004; Chase and Thomas 2006). However, in the case of Hulunbuir dune field, we suggest that the OSL ages from the top of thick paleosol layers could provide a maximum age estimate of the overlying aeolian sand and that the OSL ages of the base of the paleosol could provide a minimum age estimate of the underlying aeolian sand. Thus, the aeolian sand and paleosol share very similar age distributions. Furthermore, because the OSL ages older than $4 \mathrm{ka}$ in the paleosol are generally located at the bottom of thick paleosol layers, most of them should represent the deposition time of the soil parent material (i.e., aeolian sand). Specifically, the OSL age hiatus evident in both aeolian sand and paleosol during the interval from 5-7 ka indicates that aeolian processes in Hulunbuir ceased almost completely because of the high degree of vegetation cover and rapid soil development. In addition, the effects of wind erosion, aeolian sand input and bioturbation became minimal; i.e., the probability of aeolian sand exposure to sunlight was extremely low which would result in an age hiatus for both aeolian sand and paleosol. Therefore, this period may have experienced the most abundant precipitation, together with the highest effective humidity and vegetation coverage, in the Hulunbuir dune field since the LGM.

\subsection{Sand dune mobility and its implications for EASM precipitation and impact on human activity}

The distribution of OSL ages of aeolian sand and paleosol from the Hulunbuir dune field leads us to conclude that, following the cold (subzero) and dry climate during the LGM, the climate became warmer and more humid during the last deglaciation and early Holocene. As a consequence, soil development commenced which resulted in the stabilization and preservation of aeolian sand. However, the continuous accumulation of aeolian sand during this interval indicates that mobile dunes were still widely distributed in the Hulunbuir dune field and that 
the land surface was not completely stabilized by vegetation. The number of OSL ages of both aeolian sand and paleosol sharply decrease during the $\mathrm{HO}(9-5 \mathrm{ka})$, indicated by a minimum in probability density and an apparent age hiatus during 7-5 ka. This suggests that soils developed rapidly and that the sand dunes were almost wholly stabilized and aeolian reactivation was minimal. However, aeolian activity recommenced in the late Holocene, indicated by the reappearance of aeolian sand and the occurrence of weakly developed paleosol as the dominant soil type. This indicates that the climate was cold and dry during the late Holocene.

Changes in aeolian activity and pedogenesis in the Hulunbuir dune field since the last deglaciation are in accord with sedimentary records from other dune fields in northern China, almost all of which show that aeolian activity was intense under the harsh climate from the last deglaciation, and that the extensive development of sandy paleosol occurred during the mid-Holocene (5-7 ka), indicating weaker aeolian activity and stronger monsoon precipitation (Lu et al., 2005, 2013a,b; Sun et al., 2006a; Zhou et al., 2008, 2009; Mason et al., 2009; Yang et al., 2010; He et al., 2013). However, previous results of OSL dating in the Hulunbuir dune field suggested that it was mainly stabilized in the early Holocene (Li et al., 2002; Yang and Ding, 2013), which is inconsistent with our results. We suggest that the main reason for the disagreement lies in the different paleoclimatic interpretation of paleosol. In the previous studies, the OSL ages of the paleosol were simply regarded as indicative of the timing of soil development rather than as the maximum age estimate for the overlying aeolian sand or the minimum age estimate for the underlying aeolian sand. In addition, the authors' conclusions were drawn from the OSL dating results of only a small number of isolated sections rather than from a comprehensive compilation of OSL ages from a large number of sections, such as we present here.

A pollen-based quantitative paleoclimatic reconstruction from a sediment core from Hulun Lake (Fig. 1a) indicated that precipitation was low in the early Holocene, increased significantly in the middle Holocene (8-4.4 ka), and became drier after $4.4 \mathrm{ka}$ (Wen et al., 2010). Given the measurement error, this record is consistent with our own results. A well-dated high-resolution pollen-based quantitative precipitation reconstruction from Gonghai Lake (Fig. 7b) in North China revealed a monsoon maximum from $\sim 7.8-5.3 \mathrm{ka}$ and a rapid decline after $\sim 3.3 \mathrm{ka}$ (Chen et al., 2015). The reconstructed lake level from Dali Lake (Fig. 7b) also indicated maximum Holocene lake levels during 5.5-8 ka (Goldsmith et al., 2017). Records of MS and organic carbon isotope composition $\left(\delta^{13} \mathrm{C}\right)$ of the loess-paleosol sequence of the Chinese Loess Plateau, with independent OSL dating, also showed that peak Holocene EASM strength occurred from 8-3 ka (Lu et al., 2013a). In addition, a reconstruction of effective moisture in the deserts of northern China, combined with records of the sedimentary facies of aeolian deposits and vegetation records, demonstrated that the environment gradually became wetter from $16-8 \mathrm{ka}$, with effective moisture reaching a peak from 8-4 ka, and that relatively arid conditions prevailed after $4 \mathrm{ka}$ (Li et al., 2014). In addition, Liu et al. (2015), from an assessment of a diverse range of proxy paleoclimatic records from northern China, suggested that the majority of Holocene EASM records from northern China indicates a mid-Holocene EASM maximum.

Because peak Northern Hemisphere summer insolation (Fig. 7c) occurred during 11-10 ka (Berger and Loutre, 1991), these reconstructed results indicate that the EASM could not have responded directly to Northern Hemisphere summer insolation on the orbital scale, but that it lagged peak summer insolation by $\sim 4-3 \mathrm{ka}$. Thus, these paleoclimatic records are very different from the stalagmite oxygen isotope $\left(\delta^{18} \mathrm{O}\right)$ records (Fig. $7 \mathrm{c}$ ) which indicate a rapid monsoonal response to insolation forcing in the early Holocene (Yuan, 2004; Dykoski et al., 2005; Wang, 2005). However, the stalagmite $\delta^{18} \mathrm{O}$ record from the EASM region may not be a reliable indicator of the strength of the EASM (Liu et al., 2015), and its paleoclimatic interpretation needs further investigation.

The forcing mechanism of the lagged response of the EASM precipitation maximum to peak insolation forcing has also been intensively debated. Experiments with the coupled ocean-atmosphere FOAM (Fast Ocean Atmosphere Model) model indicated that a dynamic link between enhanced diabatic heating in the core region of the EASM and increased subsidence in the dryland region, combined with high evapotranspiration rates due to high summer temperatures, could result in the low effective moisture and sand mobility during the early Holocene in the dune fields of northern China (Mason et al., 2009). Sensitivity simulations with the Kiel Climate Model (KCM) demonstrated that melting of the remnant Laurentide ice sheet, which delivered large volumes of freshwater to the North Atlantic until $\sim 7 \mathrm{ka}$, would have weakened the Atlantic Meridional Overturning Circulation (AMOC) and thus depressed the insolation-driven EASM through the strengthening of westerly and northerly winds during the early Holocene (Chen et al., 2015). In addition, results from the TraCE- 21000 model indicated that the temporal pattern of EASM precipitation is more consistent with a response to high-northern-latitude temperature and was forced primarily by $\mathrm{CO}_{2}$ (Lu et al., 2013a). Although many studies have proposed various forcing mechanisms of the EASM based on the results of model simulations, the accuracy of these simulation experiments largely depends on the validity of the quantitative reconstruction of the boundary conditions and the resolution and complexity of the model. Therefore, continuous improvement and development of numerical models is needed to reveal unambiguously the forcing mechanism of EASM variability since the last deglaciation. Our study area is located on the northern edge of the East Asian monsoon region, where existing paleoclimatic records are very scarce, and our results provide direct records of East Asian monsoon precipitation since the last deglaciation in the mid-high-latitude-monsoon margin, and they can be used as a reference to evaluate the results of future model simulations.

The OSL ages of the aeolian sand in the Hulunbuir dune field are concentrated in the interval of $<1 \mathrm{ka}$, and in addition the peaks in PD between 1.2-0.7 ka and between 0.25-0 ka are higher than any of the other peaks (Fig 7a). The PD peak from 1.2-0.7 ka corresponds to the Medieval Warm Period (MWP, AD 800-1300). A series of paleoclimatic reconstructions and model simulations showed that the EASM in northern China generally intensified, and precipitation increased, during the MWP (e.g., Zhang et al., 2008; Liu et al., 2011; Chen et al., 2015). If dune activity and pedogenesis in Hulunbuir dune field were controlled entirely by climate change, they should have been stabilized under the warm and humid climate of MWP, and the aeolian activity should have be weakened. Therefore, we believe that climate change was not the only factor controlling dune activity in the late Holocene, and that the intensification of human activity could have led to the large-scale destruction of the steppe vegetation, resulting in strengthened wind erosion of the soils developed during the mid-Holocene, ultimately enhancing dune mobility (Sun, 2000; Lu et al., 2013b). It is noteworthy that the nomadic peoples of northern China became more prosperous during the MWP, and they successively established the Liao (AD 916-1125), Jin (AD 1115-1234) and Yuan (AD 1271-1368) Dynasties, and that cities and towns were established in the Hulunbuir dune field (represented today for example by the ruins of the cities of Bayanula, Ganzhuhua, and Haotetaohai). This, together with the related increase in agricultural production, signifies a dramatic increase in the intensity of human activity (Zhuo et al., 2013). Historical documents show that the Han nationality started to emigrate from the Central Plains region to the Hulunbuir dune field from AD 1697, leading to a large-scale land reclamation and grazing activity could have been responsible for an unprecedented degree of vegetation destruction and damage to topsoil (Li and Sun, 2006). The PD peak of 0.25-0 ka corresponds to this phase of large-scale development of agriculture and animal husbandry during the last three hundred years in Hulunbuir dune field. Therefore, our results provide new evidence for the impact of human activities on the environment in the semi-arid 

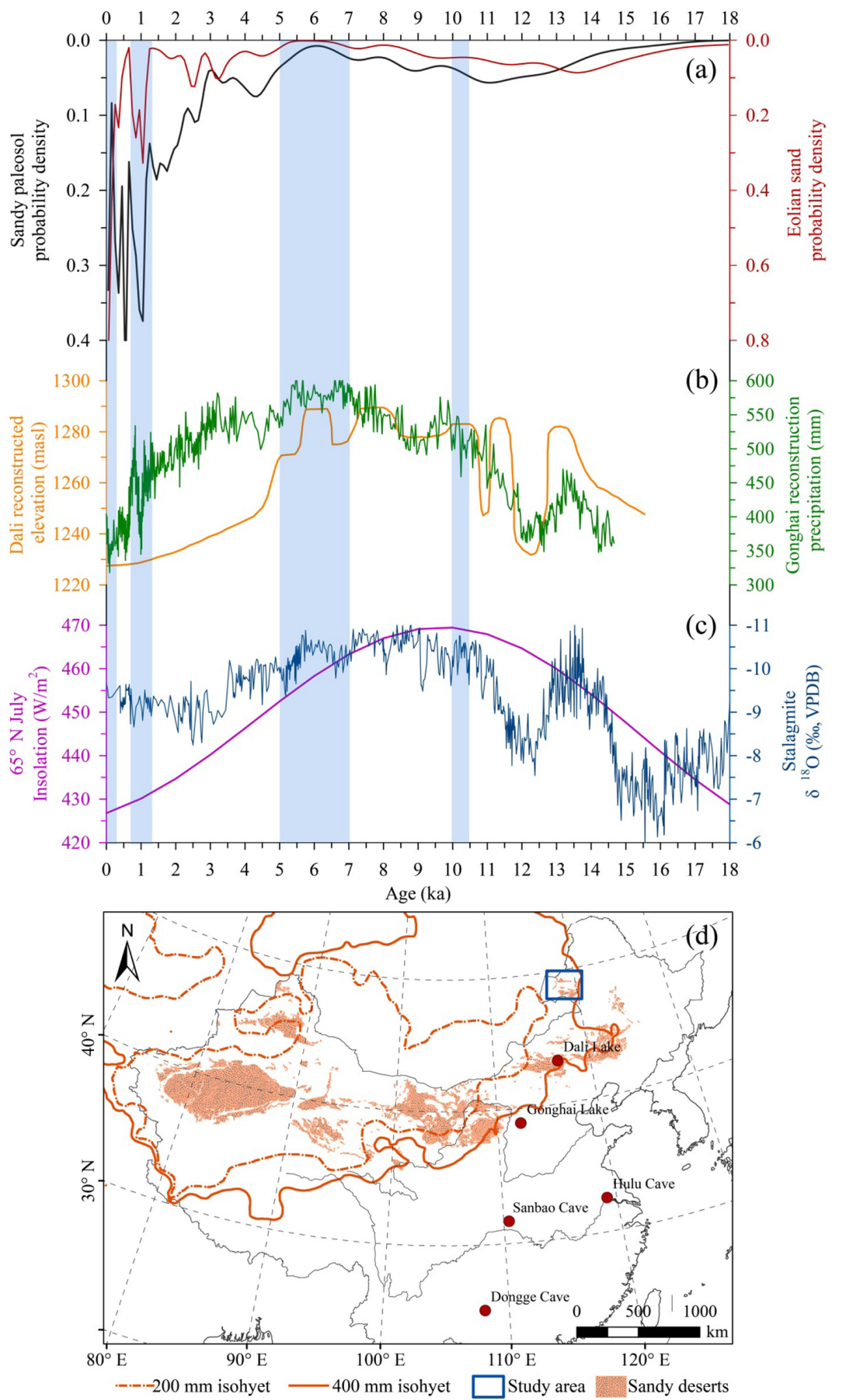

Fig. 7. Comparison of probability density (PD) of the sandy paleosol and aeolian sand in Hulunbuir dune field (a) with East Asian summer monsoon (EASM) proxy records and insolation forcing; (b) quantitative precipitation reconstruction derived from a pollenbased transfer function from Gonghai Lake (Chen et al., 2015) and the reconstructed lake level from Dali Lake (Goldsmith et al., 2017) at the modern northwestern edge of the EASM; (c) composite stalagmite oxygen isotope $\left(\delta^{18} \mathrm{O}\right)$ record from Sanbao, Hulu and Dongge caves in China (Cheng et al., 2016) and $65^{\circ} \mathrm{N}$ July insolation (Berger and Loutre, 1991); (d) location of the proxy records mentioned in the text. Blue shaded bars indicate peak insolation (11-10 ka), EASM maximum (7-5 ka), and periods of intensified human activity (1.2-0.7 ka and 0.25-0 ka). 
of silt and clay have probably contributed to the ferrimagnetic mineral assemblage during pedogenesis, since soil formation is relatively weak because of the poor hydrothermal conditions in the Hulunbuir dune field. In the studied profiles, the MS is a more sensitive indicator of pedogenesis than the grain size.

(2) A PD plot of OSL dates reveals the almost complete absence of OSL ages of aeolian sandcorresponding to the LGM. We suggest that a plausible explanation for this is that net accumulation during the LGM was limited by intensive aeolian activity. In addition, it is possible that the widely developed permafrost in the northern Chinese dune fields could have reduced the supply of sand for deflation and thus led to the limited formation of mobile dunes. Moreover, the base of the aeolian sand was not completely exposed in most of our sampling sections, which prevented our obtaining OSL ages for the deeper buried aeolian sand.

(3) We concur with the viewpoint that the clusters of OSL ages from the aeolian sand represent periods of widespread and intensive aeolian activity. However, we suggest that the OSL ages from the top of thick paleosol are a maximum age estimate of the overlying aeolian sand, while the OSL ages of the base of the paleosol are a minimum age estimate of the underlying aeolian sand. Thus, the aeolian sand and paleosol in the Hulunbuir dune field have very similar OSL age distributions.

(4) An OSL age hiatus in both aeolian sand and paleosol during 5-7 ka may indicate that the aeolian processes in Hulunbuir ceased almost entirely during this interval, which likely corresponds to the peak in EASM strength. Thus, our results provide new evidence for the delayed response of the EASM maximum to peak insolation forcing (11-10 ka) in the mid-latitude monsoon margin.

(5) A peak in PD of the OSL ages of the aeolian sand between 1.2-0.7 ka corresponds to the MWP (AD 800-1300), which indicates the occurrence, counter-intuitively, of intensified dune activity under a warm and humid climate. Thus, we suggest that climate change was not the only factor controlling dune mobility in the late Holocene and that the intensification of human activity could have led to large-scale destruction of the steppe vegetation and the reactivation of previously stable dunes. Supported by archeological evidence and historical documents, we speculate that the PD peaks from $1.2-0.7 \mathrm{ka}$ and from $0.25-0 \mathrm{ka}$ correspond to increased population increase and the development of agriculture and animal husbandry in the Hulunbuir dune field.

Supplementary data to this article can be found online at https:// doi.org/10.1016/j.gloplacha.2018.06.001.

\section{Acknowledgments}

We thank Fangying Zhu, Mingzhao Yu, Chuanbin Yang for their help with field sampling and with the laboratory measurements. Xiaoyong Wang, Xuefeng Sun, Hongyan Zhang, Xin Jia and Linhai Yang provided helpful advice. This work was funded by the Global Change Program of Ministry of Science and Technology of China (grant 2016YFA0600503), the National Natural Science Foundation of China (grants 41690111, 41472138, 41701263), and by the China Postdoctoral Science Foundation (grants 2017M611942, 2017M611943).

\section{References}

Aitken, M.J., 1998. An introduction to Optical Dating: The dating of Quaternary sediments by the use of photon-stimulated luminescence. Oxford University Press.

An, Z.S., Kukla, G.J., Porter, S.C., Xiao, J.L., 1991. Magnetic susceptibility evidence of monsoon variation on the Loess Plateau of central China during the last 130,000 years. Quaternary Res. 36, 29-36.

An, Z., Wu, G., Li, J., Sun, Y., Liu, Y., Zhou, W., Cai, Y., Duan, A., Li, L., Mao, J., Cheng, H., Shi, Z., Tan, L., Yan, H., Ao, H., Chang, H., Feng, J., 2013. Global monsoon dynamics and climate change. Annu. Rev. Earth Planet. Sc. 43, 2.1-2.49.

Balsam, W.L., Ellwood, B.B., Ji, J., Williams, E.R., Long, X., El Hassani, A., 2011. Magnetic susceptibility as a proxy for rainfall: worldwide data from tropical and temperate climate. Quat. Sci. Rev. 30, 2732-2744.

Barakat, H.N., 2009. Arid lands: challenges and hopes. In: Vaclav, C., Rachel, H.S. (Eds.), Earth System: History and Natural Variability. vol. III EOLSS Publishers, Oxford.

Berger, A., Loutre, M.F., 1991. Insolation values for the climate of the last 10000000 years. Quat. Sci. Rev. 10, 297-317.

Blott, S.J., Pye, K., 2001. GRADISTAT: a grain size distribution and statistics package for the analysis of unconsolidated sediments. Earth Surf. Proc. Land. 26, 1237-1248.

Bøtter-Jensen, L., Thomsen, K.J., Jain, M., 2010. Review of optically stimulated luminescence (OSL) instrumental developments for retrospective dosimetry. Radiat. Meas. 45, 253-257.

Charney, J., Quirk, W.J., Chow, S.H., Kornfield, J., 1977. A comparative study of effects of albedo change on drought in semi-arid regions. J. Atmos. Sci. 34, 1366-1385.

Chase, B., 2009. Evaluating the use of dune sediments as a proxy for palaeo-aridity: a southern African case study. Earth Sci. Rev. 93, 31-45.

Chase, B.M., Thomas, D.S.G., 2006. Late Quaternary dune accumulation along the western margin of South Africa: distinguishing forcing mechanisms through the analysis of migratory dune forms. Earth Planet. Sci. Lett. 251, 318-333.

Chen, F., Xu, Q., Chen, J., Birks, H.J.B., Liu, J., Zhang, S., Jin, L., An, C., Telford, R.J., Cao, X., Wang, Z., Zhang, X., Selvaraj, K., Lu, H., Li, Y., Zheng, Z., Wang, H., Zhou, A., Dong, G., Zhang, J., Huang, X., Bloemendal, J., Rao, Z., 2015. East Asian summer monsoon precipitation variability since the last deglaciation. Sci. Rep.-UK 5, 11186.

Cheng, H., Edwards, R.L., Sinha, A., Spötl, C., Yi, L., Chen, S., Kelly, M., Kathayat, G., Wang, X., Li, X., Kong, X., Wang, Y., Ning, Y., Zhang, H., 2016. The Asian monsoon over the past 640,000 years and ice age terminations. Nature 534, 640-646.

Clemens, S.C., Prell, W.L., Sun, Y., 2010. Orbital-scale timing and mechanisms driving Late Pleistocene Indo-Asian summer monsoons: Reinterpreting cave speleothem $\delta^{18}$ O. Paleoceanography 25, PA4207.

Cook, E.R., Anchukaitis, K.J., Buckley, B.M., D'Arrigo, R.D., Jacoby, G.C., Wright, W.E., 2010. Asian monsoon failure and megadrought during the last millennium. Science 328, 486-489.

Dickinson, R.E., 1983. Land surface processes and climate-surface albedos and energy balance. Adv. Geophys. 25, 305-353.

Ding, Z.L., Yu, Z.W., Yang, S.L., Sun, J.M., Xiong, S.F., Liu, T.S., 2001. Coeval changes in grain size and sedimentation rate of aeolian loess, the Chinese Loess Plateau. Geophys. Res. Lett. 28, 2097-2100.

Ding, Z.L., Derbyshire, E., Yang, S.L., Sun, J.M., Liu, T.S., 2005. Stepwise expansion of desert environment across northern China in the past 3.5 Ma and implications for monsoon evolution. Earth Planet. Sci. Lett. 237, 45-55.

Dong, G., Jia, X., An, C., Chen, F., Zhao, Y., Tao, S., Ma, M., 2012. Mid-Holocene climate change and its effect on prehistoric cultural evolution in eastern Qinghai Province, China. Quat. Res. 77, 23-30.

Duller, G., 2003. Distinguishing quartz and feldspar in single grain luminescence measurements. Radiat. Meas. 37, 161-165.

Dykoski, C., Edwards, R., Cheng, H., Yuan, D., Cai, Y., Zhang, M., Lin, Y., Qing, J., An, Z. Revenaugh, J., 2005. A high-resolution, absolute-dated Holocene and deglacial Asian monsoon record from Dongge Cave, China. Earth Planet. Sci. Lett. 233, 71-86.

Folk, R.L., 1971. Longitudinal dunes of northwestern edge of Simpson-Desert, Northern Territory, Australia. 1. Geomorphlogy and grain size relationships. Sedimentology 16, 5-54.

Folk, R.L., Ward, W.C., 1957. Brazos river bar: a study in the significance of grain size parameters. J. Sed. Petrol. 27, 3-26.

Folk, R.L., Andrews, P.B., Lewis, D.W., 1970. Detrital sedimentary rock classification and nomenclature for use in New zealand. New Zeal. J. Geol. Geop. 13, 937-968.

Goble, R.J., Mason, J.A., Loope, D.B., Swinehart, J.B., 2004. Optical and radiocarbon ages of stacked paleosols and dune sands in the Nebraska Sand Hills, USA. Quat. Sci. Rev. $23,1173-1182$.

Goldsmith, Y., Broecker, W.S., Xu, H., Polissar, P.J., Demenocal, P.B., 2017. Northward extent of East Asian monsoon covaries with intensity on orbital and millennial timescales. Proc. Natl. Acad. Sci. U. S. A. 114, 1817-1821.

Goudie, A.S., Allchin, B., Hegde, K.T.M., 1973. The former extensions of the great Indian sand desert. Geogr. J. 139 (243-25), 7.

Grün, R., 2009. The "AGE" program for the calculation of luminescence age estimates. Ancient TL 27, 45-46.

Guo, Z.T., Ruddiman, W.F., Hao, Q.Z., Wu, H.B., Qiao, Y.S., Zhu, R.X., Peng, S.Z., Wei, J.J., Yuan, B.Y., Liu, T.S., 2002. Onset of Asian desertification by $22 \mathrm{Myr}$ ago inferred from loess deposits in China. Nature 416, 159-163.

Guo, Z.T., Berger, A., Yin, Q.Z., Qin, L., 2009. Strong asymmetry of hemispheric climates during MIS-13 inferred from correlating China loess and Antarctica ice records. Clim. Past 5, 21-31.

Guo, J., Wang, T., Xue, X., Ma, S., Peng, F., 2010. Monitoring aeolian desertification process in Hulunbir grassland during 1975-2006, Northern China. Environ. Monit. Assess. 166, 563-571.

Halfen, A.F., Johnson, W.C., Hanson, P.R., Woodburn, T.L., Young, A.R., Ludvigson, G.A., 2012. Activation history of the Hutchinson dunes in east-central Kansas, USA during the past 2200 years. Aeolian Res. 5, 9-20.

Hao, Q., Oldfield, F., Bloemendal, J., Guo, Z., 2008. Particle size separation and evidence for pedogenesis in samples from the Chinese Loess Plateau spanning the past $22 \mathrm{~m}$.y. Geology 36, 727-730.

Hao, Q.Z., Wang, L., Oldfield, F., Peng, S.Z., Qin, L., Song, Y., Xu, B., Qiao, Y.S., Bloemendal, J., Guo, Z.T., 2012. Delayed build-up of Arctic ice sheets during 400,000-year minima in insolation variability. Nature 490, 393-396.

He, Z., Zhou, J., Lai, Z., Yang, L., Liang, J., Long, H., Ou, X., 2010. Quartz OSL dating of sand dunes of Late Pleistocene in the Mu Us Desert in northern China. Quat. 
Geochronol. 5, 102-106

He, Z., Zhou, J., Yang, L.H., He, H.M., 2013. Holocene dune mobility and forcing mechanisms at the Northern margin of the East Asian Monsoon. Acta Geol. Sin. Engl. 87, 1168-1178.

Hong, Y.T., Wang, Z.G., Jiang, H.B., Lin, Q.H., Hong, B., Zhu, Y.X., Wang, Y., Xu, L.S., Leng, X.T., Li, H.D., 2001. A 6000-year record of changes in drought and precipitation in northeastern China based on a $\delta^{13} \mathrm{C}$ time series from peat cellulose. Earth Planet. Sc. Lett. 185, 111-119.

Jickells, T.D., An, Z.S., Andersen, K.K., Baker, A.R., Bergametti, G., Brooks, N., Cao, J.J., Boyd, P.W., Duce, R.A., Hunter, K.A., Kawahata, H., Kubilay, N., LaRoche, J., Liss, P.S., Mahowald, N., Prospero, J.M., Ridgwell, A.J., Tegen, I., Torres, R., 2005. Global iron connections between desert dust, ocean biogeochemistry, and climate. Science 308, 67-71.

Jin, H., Chang, X., Guo, D., Yang, S., He, R., 2011. Holocene sand and soil wedges on the south central Hulunbuir high plain in northeast China (in Chinese with English abstract). Quat. Sci. 31, 765-779.

Kasse, C., 1997. Cold-climate aeolian sand-sheet formation in North-Western Europe (c.14-12.4 ka): a response to permafrost degradation and increased aridity. Permafrost Periglac. 8, 295-311.

Lancaster, N., 1981. Grain-size characteristics of Namib Desert linear dunes. Sedimentology 28, 115-122.

Lancaster, N., Hallward, J.R., 1984. A Bibliography of Desert Dunes. Department Environmental and Geographical Science, Univ, Cape Town, Cape Town.

Li, S., Sun, J., 2006. Optical dating of Holocene dune sands from the Hulun Buir Desert, northeastern China. Holocene 16, 457-462.

Li, S., Sun, J., Zhao, H., 2002. Optical dating of dune sands in the northeastern deserts of China. Palaeogeogr. Palaeocl. 181, 419-429.

Li, S.H., Sun, J., Li, B., 2012. Holocene environmental changes in central Inner Mongolia revealed by luminescence dating of sediments from the Sala Us River valley. Holocene 22, 397-404.

Li, Q., Wu, H., Yu, Y., Sun, A., Marković, S.B., Guo, Z., 2014. Reconstructed moisture evolution of the deserts in northern China since the Last Glacial Maximum and its implications for the East Asian Summer Monsoon. Global Planet. Change 121, 101-112.

Liu, T.S., Ding, Z.L., 1998. Chinese loess and the paleomonsoon. Annu. Rev. Earth Planet. Sci. 26, 111-145.

Liu, X., Shaw, J., Liu, T., Heller, F., Yuan, B., 1992. Magnetic mineralogy of Chinese loess and its significance. Geophys. J. Int. 108, 301-308.

Liu, J., Wang, B., Wang, H., Kuang, X., Ti, R., 2011. Forced response of the East Asian summer rainfall over the past millennium: results from a coupled model simulation. Clim. Dynam. 36, 323-336.

Liu, J., Chen, J., Zhang, X., Li, Y., Rao, Z., Chen, F., 2015. Holocene East Asian summer monsoon records in northern China and their inconsistency with Chinese stalagmite $\delta^{18} \mathrm{O}$ records. Earth Sci. Rev. 148, 194-208.

Livingstone, I., Bullard, J.E., Wiggs, G., Thomas, D., 1999. Grain-size variation on dunes in the southwest Kalahari, southern Africa. J. Sediment. Res. 69, 546-552.

Lu, H.Y., An, Z.S., 1997. Pretreated methods on loess-palaeosol samples granulometry. Chin. Sci. Bull. 43, 237-240.

Lu, H., Miao, X., Zhou, Y., Mason, J., Swinehart, J., Zhang, J., Zhou, L., Yi, S., 2005. Late Quaternary aeolian activity in the Mu Us and Otindag dune fields (north China) and lagged response to insolation forcing. Geophys. Res. Lett. 32, L21716.

Lu, H., Mason, J.A., Stevens, T., Zhou, Y., Yi, S., 2011. Response of surface processes to climatic change in the dunefields and Loess Plateau of North China during the late Quaternary. Earth Surf. Proc. Land. 36, 1590-1603.

Lu, H., Yi, S., Liu, Z., Mason, J.A., Jiang, D., Cheng, J., Stevens, T., Xu, Z., Zhang, E., Jin, L., Zhang, Z., Guo, Z., Wang, Y., Otto-Bliesner, B., 2013a. Variation of East Asian monsoon precipitation during the past 21 k.y. and potential $\mathrm{CO}_{2}$ forcing. Geology 41 , $1023-1026$

Lu, H., Yi, S., Xu, Z., Zhou, Y., Zeng, L., Zhu, F., Feng, H., Dong, L., Zhuo, H., Yu, K., Mason, J., Wang, X., Chen, Y., Lu, Q., Wu, B., Dong, Z., Qu, J., Wang, X., Guo, Z., 2013b. Chinese deserts and sand fields in Last Glacial Maximum and Holocene Optimum. Chin. Sci. Bull. 58, 2775-2783.

Maher, B.A., 1998. Magnetic properties of modern soils and Quaternary loessic paleosols: paleoclimatic implications. Palaeogeogr. Palaeocl. 137, 25-54.

Mason, J.A., Jacobs, P.M., 1998. Chemical and particle-size evidence for addition of fine dust to soils of the midwestern United States. Geology 26, 1135-1138.

Mason, J.A., Swinehart, J.B., Lu, H., Miao, X., Cha, P., Zhou, Y., 2008. Limited change in dune mobility in response to a large decrease in wind power in semi-arid northern China since the 1970s. Geomorphology 102, 351-363.

Mason, J.A., Lu, H., Zhou, Y., Miao, X., Swinehart, J.B., Liu, Z., Goble, R.J., Yi, S., 2009. Dune mobility and aridity at the desert margin of northern China at a time of peak monsoon strength. Geology 37, 947-950.

Murray, A.S., Wintle, A.G., 2000. Luminescence dating of quartz using an improved single aliquot regenerative dose protocol. Radiat. Meas. 32, 57-73.

Murray, A.S., Wintle, A.G., 2003. The single aliquot regenerative dose protocol: potential for improvements in reliability. Radiat. Meas. 37, 377-381.

Oldfield, F., Hao, Q., Bloemendal, J., Gibbs-Eggar, Z., Patil, S., Guo, Z., 2009. Links between bulk sediment particle size and magnetic grain-size: general observations and implications for Chinese loess studies. Sedimentology 56, 2091-2106.

Pausata, F., Battisti, D.S., Nisancioglu, K.H., Bitz, C.M., 2011. Chinese stalagmite $\delta^{18} \mathrm{O}$ controlled by changes in the Indian monsoon during a simulated Heinrich event. Nat. Geosci. 4, 474-480.

Purkait, B., 2010. The use of grain-size distribution patterns to elucidate aeolian processes on a transverse dune of Thar Desert, India. Earth Surf. Proc. Land. 35, 525-530.

Pye, K., Tsoar, H., 2009. Aeolian Sand and Sand Dunes. Springer.

Qiu, S., 2008. The Deserts and Desertification in the West of Northeastern China (in
Chineses). Science Press, Beijing.

Qiu, S., Li, Q., Xia, Y., 1992. Paleosols of sandy lands and environmental changes in the western plain of northeast China during Holocene (in Chinese with English abstract). Quat. Sci. 12, 224-232.

Rodwell, M.J., Hoskins, B.J., 1996. Monsoons and the dynamics of deserts. Q. J. Roy. Meteor. Soc. 122, 1385-1404.

Serno, S., Winckler, G., Anderson, R.F., Hayes, C.T., McGee, D., Machalett, B., Ren, H., Straub, S.M., Gersonde, R., Haug, G.H., 2014. Aeolian dust input to the Subarctic North Pacific. Earth Planet. Sci. Lett. 387, 252-263.

Shao, Y., Wyrwoll, K., Chappell, A., Huang, J., Lin, Z., McTainsh, G.H., Mikami, M., Tanaka, T.Y., Wang, X., Yoon, S., 2011. Dust cycle: nn emerging core theme in earth system science. Aeolian Res. 2, 181-204.

Shen, Y., Zhang, C., Li, Q., Jia, W., Li, J., Tian, J., 2016. Grian-size characteristics of surfer sediment in the eastern desert regions of China (in Chinese with English abstract). J. Desert Res. 36, 150-157.

Stone, A.E.C., Thomas, D.S.G., 2008. Linear dune accumulation chronologies from the southwest Kalahari, Namibia: challenges of reconstructing late Quaternary palaeoenvironments from aeolian landforms. Quat. Sci. Rev. 27, 1667-1681.

Sun, J., 2000. Origin of aeolian sand mobilization during the past 2300 years in the $\mathrm{Mu}$ US desert, China. Quat. Res, 53, 78-88.

Sun, J.M., Ding, Z.L., Liu, T.S., 1998. Desert distributions during the glacial maximum and climatic optimum: example of China. Episodes 21, 28-31.

Sun, J., Li, S., Han, P., Chen, Y., 2006a. Holocene environmental changes in the central Inner Mongolia, based on single-aliquot-quartz optical dating and multi-proxy study of dune sands. Palaeogeogr. Palaeocl. 233, 51-62.

Sun, Y., Chen, J., Clemens, S.C., Liu, Q.S., Ji, J.F., Tada, R., 2006b. East Asian monsoon variability over the last seven glacial cycles recorded by a loess sequence from the northwestern Chinese Loess Plateau. Geochem. Geophy. Geosy. 7. http://dx.doi.org/ $10.1029 / 2006$ GC001287.

Telfer, M.W., Hesse, P.P., 2013. Palaeoenvironmental reconstructions from linear dunefields: recent progress, current challenges and future directions. Quaternary Sci. Rev. $78,1-21$.

Telfer, M.W., Thomas, D.S.G., 2007. Late Quaternary linear dune accumulation and chronostratigraphy of the southwestern Kalahari: implications for aeolian palaeoclimatic reconstructions and predictions of future dynamics. Quat. Sci. Rev. 26, 2617-2630.

Thompson, R., Oldfield, F., 1986. Environmental magnetism. Allen Unwin, London.

Udden, J.A., 1914. Mechanical composition of clastic sediments. Bull. Geol. Soc. Am. 25, $655-744$.

UNDP/UNCCD, 2010. The forgotten billion: MDG achievement in the drylands. UNDP Bureau for Development Policy, New York.

Venkatesan, T.R., Ramesh, R., 1993. Consideration of analytical uncertainties while plotting histograms. J. Geol. Soc. India 41, 313-317.

Visher, G.S., 1969. Grain size distributions and depositional processes. J. Sed. Petrol. 39, 1074-1106.

Wang, P., 1992. Preliminary study on the environmental changes of Hulun Buir sandy land since the Holocene (in Chinese with English abstract). J. Desert Res. 12, 13-19.

Wang, Y., 2005. The Holocene Asian monsoon: links to solar changes and north Atlantic climate. Science 308, 854-857.

Wang, X., Dong, Z., Zhang, J., Qu, J., Zhao, A., 2003. Grain size characteristics of dune sands in the central Taklimakan Sand Sea. Sediment Geol. 161, 1-14.

Wang, P.X., Wang, B., Cheng, H., Fasullo, J., Guo, Z., Kiefer, T., Liu, Z., 2017. The global monsoon across time scales: mechanisms and outstanding issues. Earth Sci. Rev. 174 84-121.

Wen, R., Xiao, J., Chang, Z., Zhai, D., Xu, Q., Li, Y., Itoh, S., Lomtatidze, Z., 2010 Holocene climate changes in the mid-high-latitude-monsoon margin reflected by the pollen record from Hulun Lake, northeastern Inner Mongolia. Quat. Res. 73, 293-303.

Wentworth, C.K., 1922. A scale of grade and class terms for clastic sediments. J. Geol. 30, 377-392.

Wintle, A.G., Murray, A.S., 2006. A review of quartz optically stimulated luminescence characteristics and their relevance in single-aliquot regeneration dating protocols. Radiat. Meas. 41, 369-391.

Wu, Z., 2009. Sandy deserts and its control in China (in Chinese). Science Press, Beijing.

Xiao, J., Xu, Q., Nakamura, T., Yang, X., Liang, W., Inouchi, Y., 2004. Holocene vegetation variation in the Daihai Lake region of north-central China: a direct indication of the Asian monsoon climatic history. Quat. Sci. Rev. 23, 1669-1679.

Xu, Z., Lu, H., Yi, S., Vandenberghe, J., Mason, J.A., Zhou, Y., Wang, X., 2015. Climatedriven changes to dune activity during the Last Glacial Maximum and deglaciation in the Mu Us dune field, north-central China. Earth Planet. Sci. Lett. 427, 149-159.

Xu, Z., Mason, J.A., Lu, H., Yi, S., Zhou, Y., Wu, J., Han, Z., 2017. Crescentic dune migration and stabilization: Implications for interpreting paleo-dune deposits as paleoenvironmental records. J. Geogr. Sci. 27, 1341-1358.

Yaalon, D.H., Ganor, E., 1973. Influence of dust on soils during quaternary. Soil Sci. 116, $146-155$.

Yang, L., Ding, Z., 2013. Expansion and contraction of Hulun Buir Dunefield in northeastern China in the last late glacial and Holocene as revealed by OSL dating. Environ. Earth Sci. 68, 1305-1312.

Yang, L., Zhou, J., Lai, Z., Long, H., Zhang, J., 2010. Lateglacial and Holocene dune evolution in the Horqin dunefield of northeastern China based on luminescence dating. Palaeogeogr. Palaeocl. 296, 44-51.

Yang, S., Ding, Z., Li, Y., Wang, X., Jiang, W., Huang, X., 2015a. Warming-induced northwestward migration of the East Asian monsoon rain belt from the Last Glacial Maximum to the mid-Holocene. Proc. Natl. Acad. Sci. U. S. A. 112, 13178-13183.

Yang, X., Scuderi, L.A., Wang, X., Scuderi, L.J., Zhang, D., Li, H., Forman, S., Xu, Q., Wang, R., Huang, W., Yang, S., 2015b. Groundwater sapping as the cause of 
irreversible desertification of Hunshandake Sandy Lands, Inner Mongolia, northern China. Proc. Natl. Acad. Sci. U. S. A. 112, 702-706.

Yuan, D., 2004. Timing, duration, and transitions of the last interglacial Asian monsoon. Science 304, 575-578

Zeng, L., Lu, H., Yi, S., Chen, Y., Zhu, F., 2013. Environmental changes of Hulunbuir dunefield in northeastern China during the Last Glacial Maximum and Holocene Optimum (in Chinese with English abstract). Quat. Sci. 33, 243-251.

Zeng, L., Lu, H., Yi, S., Stevens, T., Xu, Z., Zhuo, H., Yu, K., Zhang, H., 2017. Long-term Pleistocene aridification and possible linkage to high-latitude forcing: New evidence from grain size and magnetic susceptibility proxies from loess-paleosol record in northeastern China. Catena 154, 21-32.

Zhang, A., Feng, Z., Wang, Xiaoke, U H, 2006. Review on research of desertification mechanism in Hulun Buir grassland, China (in Chinese with English abstract). J. Desert Res. 26, 300-306.

Zhang, P., Cheng, H., Edwards, R.L., Chen, F., Wang, Y., Yang, X., Liu, J., Tan, M., Wang, X., Liu, J., An, C., Dai, Z, Zhou, J., Zhang, D., Jia, J., Jin, L., Johnson, K.R., 2008. A test of climate, sun, and culture relationships from an 1810-year Chinese cave record. Science 322, 940-942.

Zhao, W., Sun, Y., Balsam, W., Zeng, L., Lu, H., Otgonbayar, K., Ji, J., 2015. Clay-sized HfNd-Sr isotopic composition of Mongolian dust as a fingerprint for regional to hemispherical transport. Geophys. Res. Lett. 42, 5661-5669.

Zhao, L., Ma, C., Leipe, C., Long, T., Liu, K., Lu, H., Tang, L., Zhang, Y., Wagner, M., Tarasov, P.E., 2017. Holocene vegetation dynamics in response to climate change and human activities derived from pollen and charcoal records from southeastern China.
Palaeogeogr. Palaeocl. 485, 644-660.

Zheng, H.B., Oldfield, F., Yu, L.H., Shaw, J., An, Z.S., 1991. The magnetic-properties of particle-sized samples from the Luo Chuan loess section - evidence for pedogenesis. Phys. Earth Planet. Inter. 68, 250-258.

Zhou, L.P., Oldfield, F., Wintle, A.G., Robinson, S.G., Wang, J.T., 1990. Partly pedogenic origin of magnetic variations in Chinese loess. Nature 346, 737-739.

Zhou, Y.L., Lu, H.Y., Joseph, M., Miao, X.D., James, S., 2008. Optically stimulated luminescence dating of aeolian sand in the Otindag dune field and Holocene climate change. Sci. China. Ser. D 51, 837-847.

Zhou, Y., Lu, H., Zhang, J., Mason, J.A., Zhou, L., 2009. Luminescence dating of sand loess sequences and response of Mu Us and Otindag sand fields (north China) to climatic changes. J. Quat. Sci. 24, 336-344.

Zhou, W., Zheng, Y., Meyers, P.A., Jull, A.J.T., Xie, S., 2010. Postglacial climate-change record in biomarker lipid compositions of the Hani peat sequence, Northeastern China. Earth Planet. Sci. Lett. 294, 37-46.

Zhou, X., Sun, L., Zhan, T., Huang, W., Zhou, X., Hao, Q., Wang, Y., He, X., Zhao, C. Zhang, J., Qiao, Y., Ge, J., Yan, P., Yan, Q., Shao, D., Chu, Z., Yang, W., Smol, J.P., 2016. Time-transgressive onset of the Holocene Optimum in the East Asian monsoon region. Earth Planet. Sci. Lett. 456, 39-46.

Zhu, B., Yu, J., Rioual, P., Ren, X., 2014. Particle size variation of aeolian dune deposits in the lower reaches of the Heihe River basin, China. Sediment. Geol. 301, 54-69.

Zhuo, H., Lu, H., Jia, X., Sun, Y., 2013. A preliminary study on human activities in sand fields of northern China and its relationship with the climatic variations in Holocene (in Chinese with English abstract). Quat. Sci. 33, 303-313. 